\title{
Delaying moving away: Place, mobility, and the multimodal organization of activities
}

Mathias Broth and Lorenza Mondada

The self-archived postprint version of this journal article is available at Linköping University Institutional Repository (DiVA):

http:/ / urn.kb.se/ resolve?urn=urn:nbn:se:liu:diva-159893

N.B.: When citing this work, cite the original publication.

Broth, M., Mondada, L., (2019), Delaying moving away: Place, mobility, and the multimodal organization of activities, J ournal of Pragmatics, 148, 44-70.

https:// doi.org/ 10.1016/j.pragma.2019.05.013

Original publication available at:

https:// doi.org/ 10.1016/j.pragma.2019.05.013

Copyright: Elsevier

http:// www.elsevier.com/

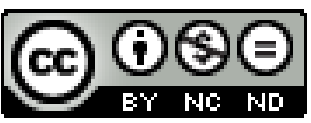




\title{
Delaying moving away: Place, mobility, and the multimodal organization of activities ${ }^{1}$
}

\author{
Mathias Broth ${ }^{\mathrm{a}}$, Lorenza Mondada ${ }^{\mathrm{b}}$ \\ ${ }^{\mathrm{a}}$ University of Linköping, Department of Culture and Communication (IKK), Campus Valla Hus Key, S 581 83, Linköping, Sweden \\ ${ }^{\mathrm{b}}$ University of Basel, Department for Linguistics and Literature, French Studies, Maiengasse 51, CH 4056, Basel, Switzerland
}

\begin{abstract}
In mobile activities alternating between staying at a place and walking to the next place, such as guided visits, the initiation of walking away is a powerful practice to achieve closing of conversational sequences and courses of action. This was demonstrated in a previous paper (Broth \& Mondada, 2013): in this follow-up paper, we elaborate on the options that can be responsive to walking away, by focusing on actions that co-participants make in order to momentarily stop it, occasioning a delayed departure/closing. Delaying walking away may be done, accountably, either as a continuation of the previous course of action, or as an initiation of a new course of action related to the present local position of the participants. The study is based on a large corpus of visits to different places and for diverse purposes, in French, Swedish and English. It also shows how trajectories of walking, their projections and their obstacles, are exemplary embodied practices revealing fundamental features of sequential organization e crucially related to the progressivity of talk, actions, and activities.
\end{abstract}

Keywords:

Conversation analysis; Multimodality; Mobility; Walking; Sequence closing; Progressivity; Delaying

\section{Introduction}

In a previous article published in this journal (Broth and Mondada, 2013), we demonstrated how, in mobile activities that alternate between staying at one place and walking to the next place, the initiation of walking away is a powerful practice to achieve closing of conversational sequences and courses of action. In this follow-up paper, we focus on actions that coparticipants perform when walking away is being projected and initiated, and which temporarily stop it, thus producing a delayed departure. Within the framew ork of ethnomethodology and conversation analysis, this study, like the first, focuses on trajectories of walking, their projections, and their obstacles, as exemplary embodied practices revealing fundamental features of sequential organization. As such, they are crucially related to the progressivity of talk, actions, and activities. As we will show, delaying walking away may be done, accountably, by actions that either continue the previous course of action, or initiate a new course of action related to the local position of the participants. That such actions delay what walking away projects as the next action is manifest in the variety of ways in which initiators of walking away respond to them.

\subsection{Walking, progressivity, and the negotiable character of activity closings}

Research on social interaction, in particular in conversation analysis and ethnomethodology (EMCA), has long taken an interest in closings, i.e., the ending of focused encounters. Schegloff and Sacks (1973) detail how closing telephone

\footnotetext{
${ }^{1}$ Please refer to this article as: Broth, M, \& Mondada, L. (2019). Delaying Moving Away. Place, mobility, and the multimodal organization of activities. Journal of Pragmatics 148, 44-70. Page numbers and page breaks correspond to published journal version. https://doi.org/10.1016/i.pragma.2019.05.013
}

This work is licensed under the Creative Commons Attribution-NonCommercial-NoDerivs 4.0 International License. To view a copy of this license, visit https://creativecommons.org/licenses/by-nc-nd/4.0/ or send a letter to Creative Commons, PO Box 1866, Mountain View, CA 94042, USA. 

conversations is an interactional achievement taking place over a series of turns and sequences, whereby participants coordinate in bringing the continuous alternating of turns to an end (Sacks et al., 1974) before they actually hang up. Closings have, however, also been shown to be negotiable: as closings of conversations have a routine character and are thus projectable, it is possible for participants who understand that a move is being made toward closing to align with it, or, alternatively, to delay or postpone it (Schegloff and Sacks, 1973; Davidson, 1978; Button, 1987; Bolden, 2008).

In situations where participants are co-present or otherwise available to each other in other ways than just verbally, closings and delays of closings are also done in an embodied way (De Stefani, 2006; Deppermann et al., 2010; Mondada, 2015; Haddington, 2019). As we have previously shown, walking away is an embodied practice that can be initiated in and for the concerted achievement of closings in activities involving participants in co-presence and where mobility is possible and relevant (Broth and Mondada, 2013). Just like closings of, e.g., telephone conversations, the orderly closing of stationary activities is projectable, but this projectability is embodied in more diverse ways than in a voice-only context. They also require close coordination between the participants, who are demonstrably sensitive to very subtle embodied displays of their co-participants (Broth and Mondada, 2013). Just as in other conversations, this projectability enables participants to act in order to align with, but also to delay, the next action, for some practical purpose.

In activities that are essentially mobile, delaying walking away, or forward, equals delaying the "progressivity" (Schegloff, 1979:268) of the overall mobile activity. Progressivity has been suggested to be a fundamental principle of interaction, in strictly conversational terms formulated by Schegloff (1979:268) as "a structural preference for keeping next-turn position free for sequentially implicated nexts." Whereas Schegloff primarily discusses progressivity in relation to conversational repair, this principle can be reformulated in more general terms as a preference for the actual production next of that which is being projected. Anything else happening in "next position" will be inspected for its relevance (cf. Schegloff, 2007:14-15).

Recently, progressivity in this broader sense has become an important point of focus in a number of studies dealing with a variety of social actions and activities. Studying answers to questions that are addressed to a particular other party, Stivers and Robinson (2006) find that the production of an answer (by any participant) is preferred over getting an answer from the addressed party. Some studies also stress the relevance of progressivity for the achievement of social relationships among the participants involved, also over extended periods of time. Kuroshima (2010) focuses on orientations to the progressivity of food orders in a multilingual context and issues of relations and trust between customers and the chef at a sushi restaurant. Muntigl (2013) has described how a client may resist progressivity following a counselor's questions during couples counseling, and how the counselor increasingly disaligns with the client. Other studies discuss the consequences of grammatical choices for progressivity: Heritage (2013) studies turn-initial objects in relation to what they project will come next, and Keevallik (2016) considers the stalling work that is accomplished by the Estonian junction marker maitea ("I don't know"). More generally, speakers are often confronted with the conflicting demands of securing intersubjectivity and moving the business at hand forward (Heritage, 2007).

This study adds to the above body of work by highlighting the crucial contribution of embodied practices to the multimodal organization of progressivity in and through walking practices. In particular, we focus on walking as a particularly visible and accountable embodied practice (Ryave and Schenkein, 1974; Broth and Lundstrøm, 2013; Mondada, 2017), whose organization is strongly associated with progressing in interaction. Moving step-by-step embodies the way in which sequential organization is managed by the participants in an orderly and coordinated way. This is particularly observable in the kind of mobile activity that we focus on here: guided visits.

\subsection{Settings, data, and method}

This study is based on video recordings of human interactions that alternate between mobile phases, in which participants move from one place to another, and stationary phases, in which participants stop in order to engage in activities such as showing or asking about a particular aspect of the material surroundings before moving on again. This type of organization typically characterizes guided visits, as has been described in the EMCA literature (Best, 2012; Best and Hindmarsh, 2019; Birkner and Stukenbrock, 2010; De Stefani, 2010; De Stefani and Mondada, 2014, 2017; Mondada, 2014).

A first type of activities that we studied are guided tours in urban touristic spots (corpus Cooking and Tourly) and architectural monuments (corpus Archivis and Archijardivis), all of which involve the categories of "guide" and "guided" participants. We also studied other types of visits, such as construction site inspections led by engineers and architects (corpus CAB), and energy analysis tours (corpus EA), in which "energy auditors" are shown around a store, a small factory and a car-testing station by company representatives with the ultimate aim of making their electric installations consume less energy.

The languages spoken are French (corpus Tourly, Archivis, Archijardivis, CAB), Swedish (corpus EA) and English (corpus Cooking). In total, the video recordings amount to approximately $100 \mathrm{~h}$. All recordings were made with the informed consent of the participants.

Within the perspective of multimodal EMCA, the video recordings were subjected to detailed analysis of the sequentially emerging action-in-interaction. This work involved repeated viewings and detailed multimodal transcription of selected video sequences. The analysis focuses on the actions performed by the participants, and the way they are formatted, relying on verbal and embodied resources. The originality of the analysis pursued here is its focus on the entire bodies of the participants in their complexity (Goodwin, 2000, 2017) and, more particularly, on walking as a crucial practice for organizing mobile interactions (Haddington et al., 2013). 
2. The relevance of walking away for sequence closing

In this initial analytic section, we first remind the reader of the basic phenomenon of walking away as described by Broth and Mondada (2013) (§ 2.1). We then introduce the focus of this paper, delaying walking away $(\S 2.2)$.

\subsection{Walking away}

As demonstrated in Broth and Mondada (2013), beginning to walk away is a recurrent and systematic practice contributing to the embodied achievement of sequence closing in mobile interaction.

The phenomenon is observable in Excerpt 1, in which a group of energy analysts (Conny, Richard, and Anna) are shown around a building by two representatives of a local store (Mats and Lars). We join them as Richard is drawing a conclusion regarding the building's ventilation piping (lines $1 \mathrm{e} 2)$ :

(1) (EA090401-1_52m41s_52m49s)

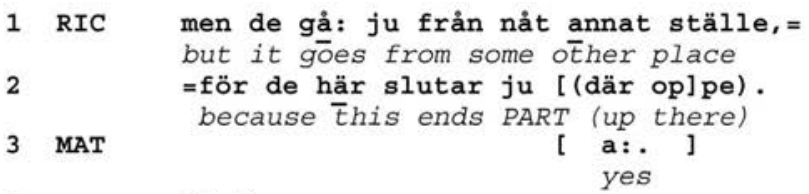

$4 \quad(1.1)$

5 RIC ka- äre de: röre som går på (up [pe)vå]:ningen\#* ( ${ }^{\circ e n}$ del $\left.{ }^{\circ}\right)$.

6 MAT ca- is thăt the pipe that is on the floor (above) (partly)

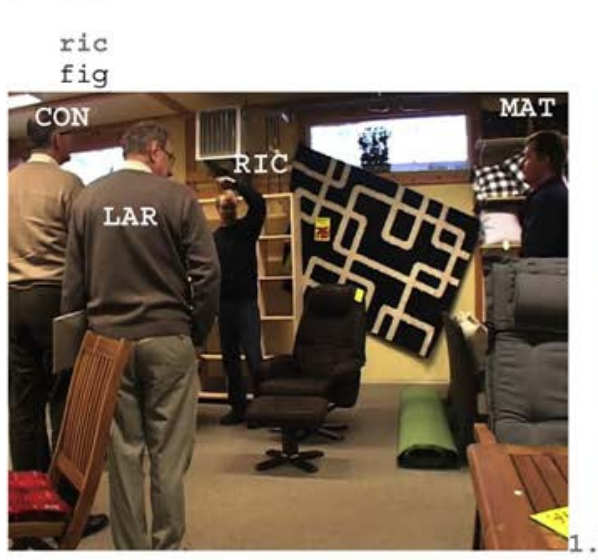
[a:o.] yes

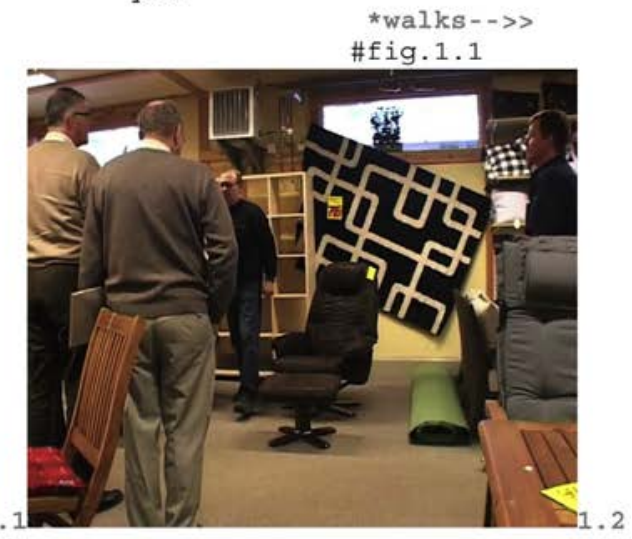

7 RIC

(. ) $\circ \circ+\% \mathrm{ke}^{\circ} \cdot \& £ \#$

okay

+walks-->>

\%weight forward, walks->>

\&turns, walks $>>$

(£turns, walks->>) ((hidden from view, by CON))

con

ann

fig

$8 \mathrm{CON}$ $\#$ fig.1.2

9 LAR

(.) $\mathrm{m}:$,

$m$

\section{fig}

(0.3) ${ }^{\circ} \cdot j a^{\circ} \# v i$ kommer ti övervåningen sen, vi ska: gå:, \# yes we'll come to the upper floor later we'll go
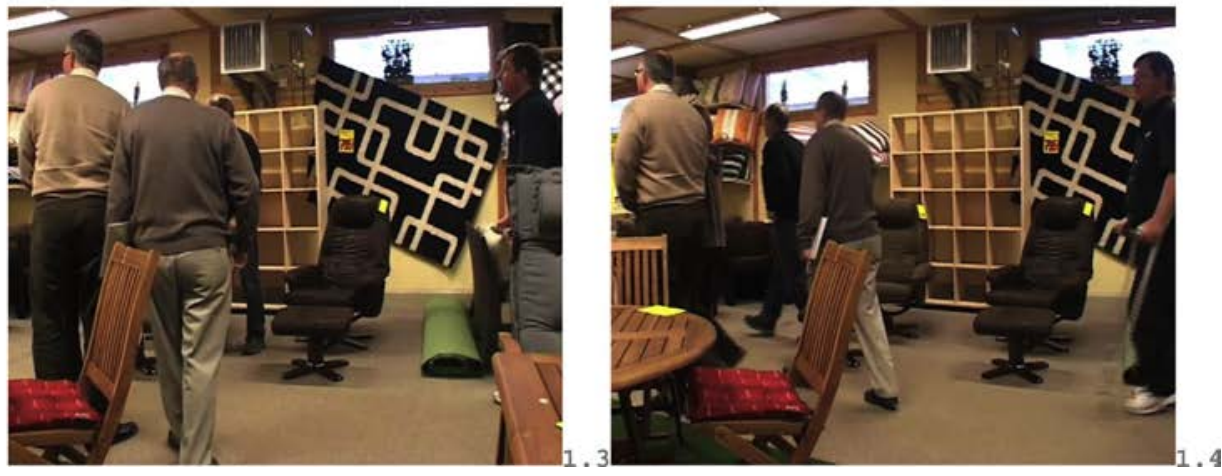
Richard's conclusion concerning the ventilation piping (1-2) is confirmed by Mats (3), the owner of the building, in overlap with Richard's ending "turn constructional unit," or "TCU” (Sacks et al., 1974). After a 1s pause, Richard then asks, pointing upwards (Figure 1.1) and gazing at Mats, whether this is the pipe that is also located on the upper floor, and Mats again confirms (5-6). This time, Mats takes his turn very "early," i.e, as the referent is becoming recognizable but still relatively far from the projectable end of Richard's TCU (5-6). By beginning to walk away (6; Figure 1.2)-even before his own questioning turn is completed-Richard treats Mats' response as having completed the question-answer sequence, and more globally, displays that he is done with questions at this location. And as Richard, taking his first step, produces a "sequence closing third" (Schegloff, 2007:118) in the form of "0 $\mathrm{oke}^{0}$.," the other participants likewise begin to move in the projected direction of the guided visit (7; Figures 1.3e1.4). As soon as the group has begun to move, Lars, one of the two company representatives, informs about where they will go next (9).

The excerpt demonstrates how participants may orient to, and actually achieve, the closing of an interactional sequence in an embodied way, not only by a particular participant's sequence-closing third turn, but also by walking away together (as shown by Broth and Mondada, 2013). Nonetheless, sequence-closing walking away does not al- ways happen in such a straightforward way. Things may turn out differently, as one of the participants may, in a variety of ways, delay an imminent or just initiated departure. This is what will interest us in the remainder of this paper.

\subsection{Speaker's orientation to walking away and possible alternative actions}

The phenomenon of walking away that we focus on occurs at possible completion points of turns-at-talk, and, more particularly, at turns achieving possible sequence closing. In this sequential environment, various options are available to the participants, which can be locally implemented but, interestingly enough, also formulated, in the sense of Garfinkel and Sacks (1970) of "saying-in-so-many words-what we-are-doing" (see also Deppermann, 2011).

The following two excerpts show local formulations of the phenomenon: in the first, a guide offers the possibility of a course of action (to ask questions) that is an alternative to walking away, and which is presented as exclusive (either walking or asking). In the second, the guide once again offers the opportunity to ask questions, but also points at the consequences of this action for the progressivity of the activity. Thus, at the end of a sequence, participants orient to a slot that can be occupied by at least two alternative courses of action. This is reflexively elaborated by them, not only in local terms (what happens next), but also in more global terms, orienting to the progressivity of the activity as a whole (Stivers and Robinson, 2006), i.e., the visit.

The next excerpt begins as the guide, Monique, launches the beginning of a walking tour in a food street in Paris, after the other participants, Alan, Ann, John, and Sylvie, have gathered together at a meeting point:

(2) (Cooking 3_3.35)

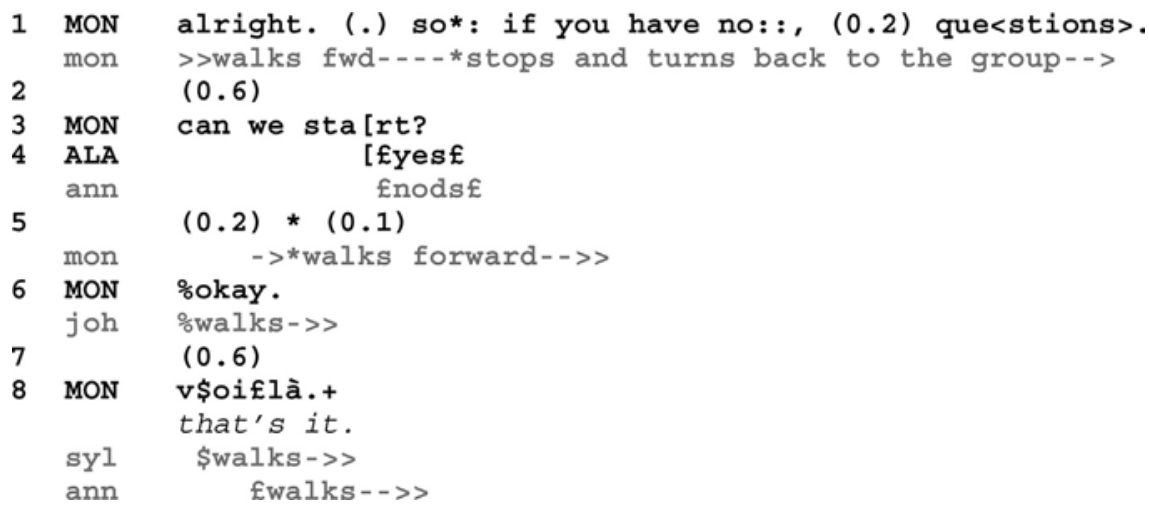

Monique has closed the sequence and begun to walk forward (not shown), but the co-participants are still immobile on the sidewalk. Her turn in line 1 orients to this fact, and offers a new occasion to either align with the closing, or to produce an alternative action. After "alright" and a micro-pause, Monique adds a new TCU, which is formatted as the first part of a compound TCU, an "if/then" construction (1). She explicitly mentions the possible insertion, at this sequential position, of a question coming from them. The opportunity to ask a question is not only formulated in so many words ("if you have no::, (0.2) que<stions>," 1), but also created multimodally by stretching the formulation (by a lengthened "no::," a pause of $0.2 \mathrm{~s}$, and a slower tempo on the last part of "que<stions>") and by stopping to walk within a general orientation toward the temporal feature of this sequential opportunity. 
Registering the fact that nobody responds to her first part, aligning with its projection of a preference for not asking any questions (2), Monique completes the second part of the compound TCU (3), not as a then-clause but as a turn requiring a goahead for the next activity to come. This part receives several positive responses (4) and consequently, the guide initiates walking (5), soon followed by the other participants (6-8).

This excerpt provides evidence that participants orient to certain positions in the unfolding activitydhere, when an explanatory sequence has been brought to completiondas positions at which the co-participants have the right to ask a question, and thereby to continue the previous activity (Mondada, 2018b). This right is part of the negotiated dimension of closings. Thus, in our excerpt, walking away is achieved not as a unilateral departure by the guide, but as a joint accomplishment.

A similar orientation is visible in other mobile contexts. The next excerpt starts at the very beginning of a visit of a construction site for citizens and activists involved in its planning. The guiding architect, Ligour, has just announced the itinerary that he proposes (not shown), and adds:

(3) (CAB21-douves-16.10)

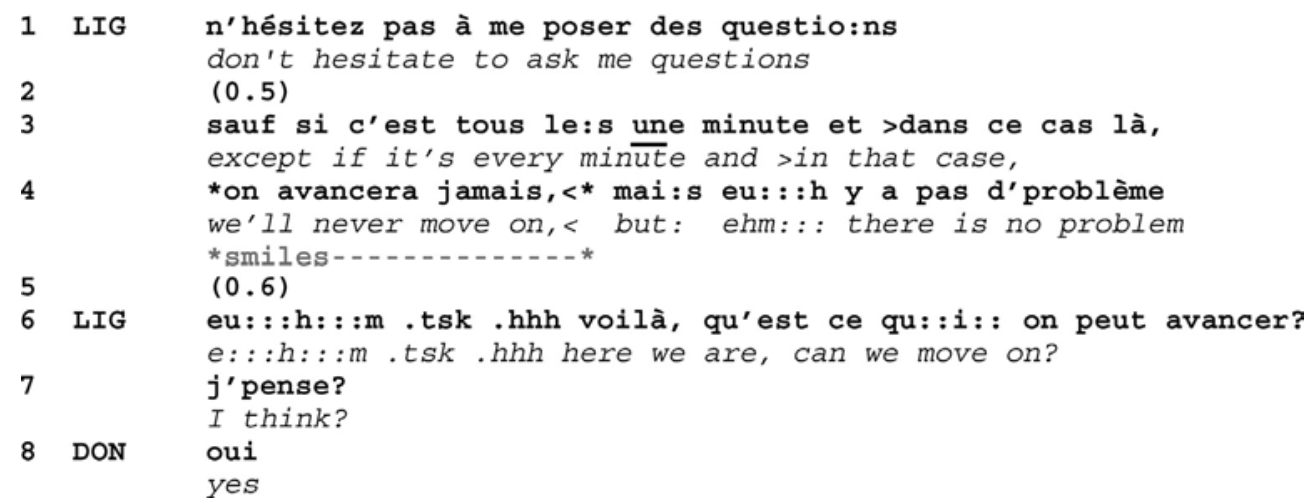

The architect encourages the group of visitors to ask questions. However, after a small gap, in which no questions are asked (2), he relativizes this offer. The syntactic and argumentative construction of his turn shows the ambivalent treatment of questions. The "problem" is topicalized as one of time (too many questions would delay the visit) and progressivity. In French, avancer means both "to progress" and "to walk forward" (as well as in Swedish and English: Kan vi gå vidare? Can we move on?). This conflates two complementary aspects: the temporal progressivityof the activity and the bodilyprogressionof the walk (Mondada, 2018b).

The previous excerpts highlight the tension between possible actions that would delay the projected next action, as well as the achievement of closing that would otherwise enable the participants to progress their global activity. In the next sections, we focus on a diversity of practices that participants use to delay the progressivity of the overall mobile activity indexed by initiating walking away.

3. The design of post-completion delaying actions

At the completion of larger phases of activity (see Sacks, 1992, vol. 2:354e359; Heritage and Maynard, 2006; Linell, 2009), such as a lengthy stationary explanation, the embodied initiation of moving away strongly projects closing, and progress toward the next phase of the activity, and exerts pressure on the co-participants to align with this.

Although a multiplicity of contingencies might delay the progressivity of the walk and the talk, in the diversity of mobile activities constituting our corpus, we observe delaying actions that systematically make the participant beginning to walk away, as well as other members of the group, slow down or stop altogether. These delaying actions-such as questions, comments, noticings and requests for confirmation-are related to the accountable management of two different aspects of context: 1) they can maintain and exploit the interactional space of the current course of action and its participation framework (3.1), and 2) theyxcan also maintain the group at a position in the local environment from which it is possible to refer to and inspect details of the local surroundings, and thus initiate alternative courses of action ( $\$ 3.2)$. 
As we will later see, co-participants may respond in different ways to actions that delay the closing of the projected activity phase. They may immediately align by stopping or slowing down their walk, or disalign with the stopping action by continuing to walk.

\subsection{Continuing the current course of action within the current interactional space}

The closing of an activity opens up a sequential slot in which participants can project the next action, in a way that implies, or not, the dissolution of the current "interactional space," i.e. the spatial configuration shaped by the bodily arrangement of the participants (Mondada, 2014). In this context, even if walking away is projected and initiated in an embodied way, coparticipants may work to maintain and exploit the current spatial arrangement of the group.

A first, relatively simple instance is the following, where a gardener (Luc) is explaining the detrimental effects of cochineal to a group of visitors that he is showing around the garden. At the end of his explanation, he begins to move forward (6). But questions by two of the visitors stop his steps:

(4) (archivis03_00.11.30_cochenille)

1 LUC c'est le: m c'est la cochenille du kermès qui servait it's the: m it's the kermes cochineal that served

2 de colorant avant, $h$ qu'on a remplacé par une cochenille

as coloring in the past.h which was replaced by a cochineal

3 qui vit sur le cactus, sur la raquette hein $(0.5)$ mais

4 that lives on cactuses, on opuntia right but euh: : parce que c'était plus facile à élever, (0.4) mais

5 ehm: : because it was easier to grow,

6 euh: celle-ci c'est une voisine, (0.4) c'est ehm: this one is a neighbor, it's

la\#*la cochenille du chène ve*rt. the the green oak cochineal

*1 step fwd-...-...--*1 step->

fig \#fig.4.1 $(0.2)$

8 ELI $\rightarrow$ et c'est pas* [•pour •ça que\# ( )]

and it's not [because of it that ( )]

9 YAN $\rightarrow \quad$ [•et qui• le\# man]*ge a[lors? *\#

10 LUC [and who eats it then

yes

luc ->*1 step fwd-------*1 step back*stops->>

luc $\quad$...... looks at ELI--->>

fig \#fig. 4.2 fig. $4.3 \#$

11 LUC si. et c'est en train de tout nous envahir et ((cont.))

yes and it's about to invade everything and

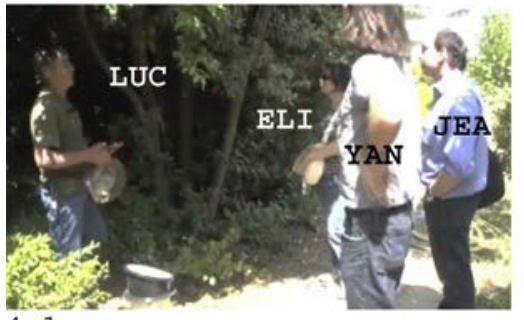

4.1

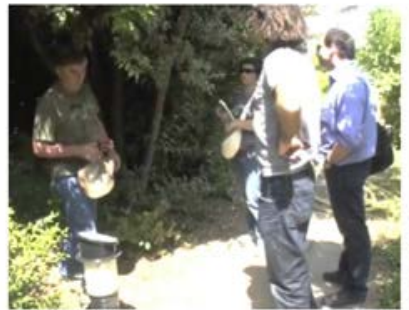

4.2

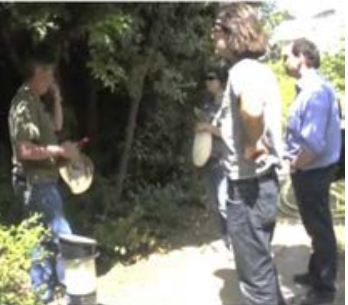

4.3

Luc finishes his explanation about the poisonous insect (4). On the last TCU, he steps forward, walking away at sequence completion. But the co-participants remain immobile and do not align with his movement (Figure 4.1). Moreover, both Elise (8) and Yan (9) ask a question at that precise moment. Both design it as an and-prefaced question (Heritage and Sorjonen, 1994; Nevile, 2006), clearly tying it to the previous explanation. Both also use anaphoric pronouns ("ça"/"that" [8]; "le"/ "it" [9]), further building a continuity with the previous turn. Luc continues for a few steps (Figure 4.2), but stops at the end of Yan's question (Figure 4.3). He looks at Elise and adopts a "lecturing" stationary posture (Figure 4.3) while responding to, and 
expanding the previous topic. The effect of the question is to prolong the previous explanation and stop Luc's incipient movement, as instead of walking away, he remains in the same place to answer the question.

In addition to and-prefaced questions, so-prefaced turns also contribute to stop moving away, and thus, to maintain the current interactional space. In the next extract, the energy auditor Richard is formulating his understanding of the current situation regarding how the air circulates in the current building (1-4), so that Mats, the owner of the business, can confirm it $(3,5)$. As in Excerpt (1) above, Richard utters a sequence-closing third "okay" and begins to walk forward, displaying that he is done with inquiries about the current location (6, Figures 5.1-5.2):

(5) (EA090401-1 48m27s-48m39s)
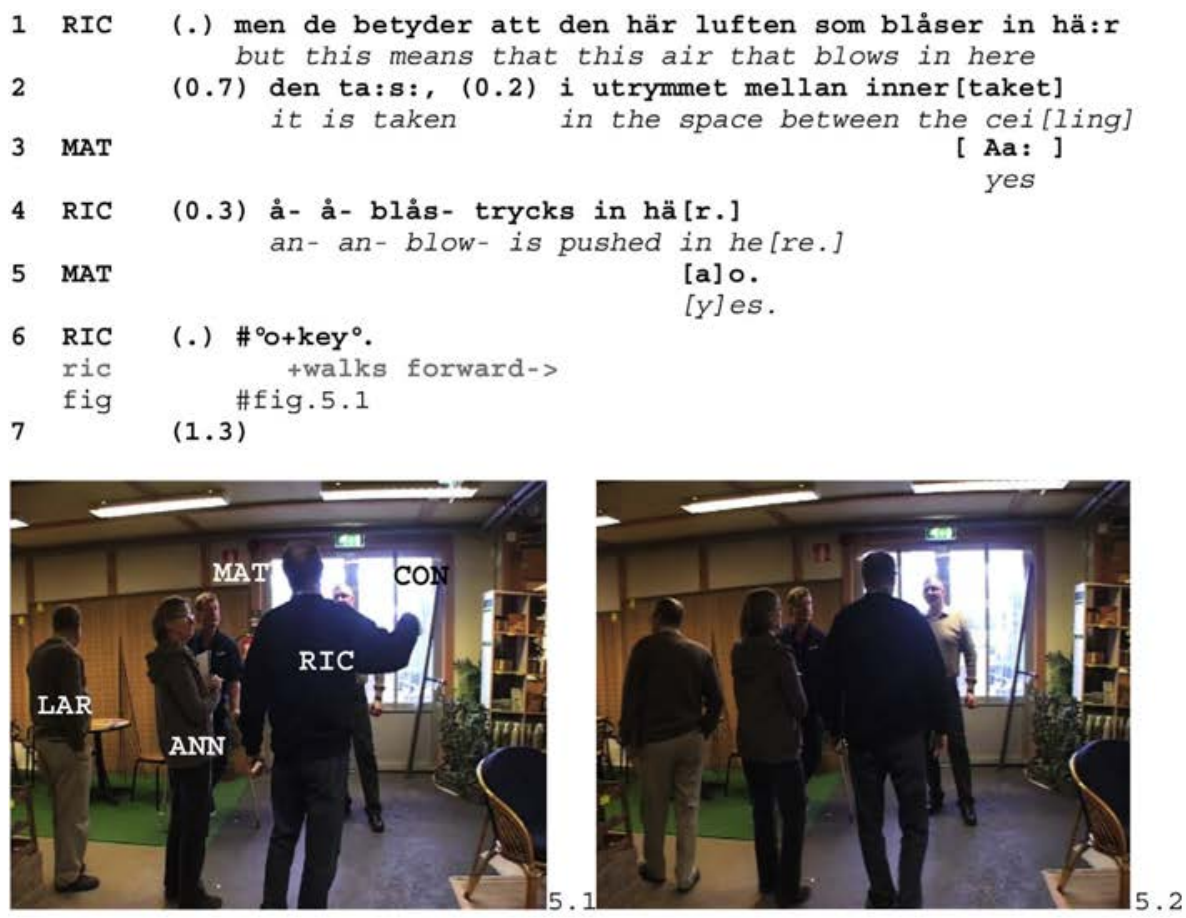
8 CON $\rightarrow$ \#tsk >så att-< ö-+

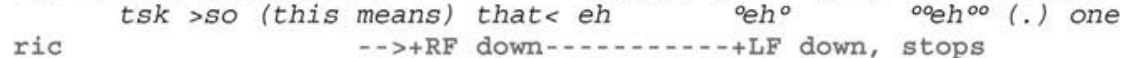

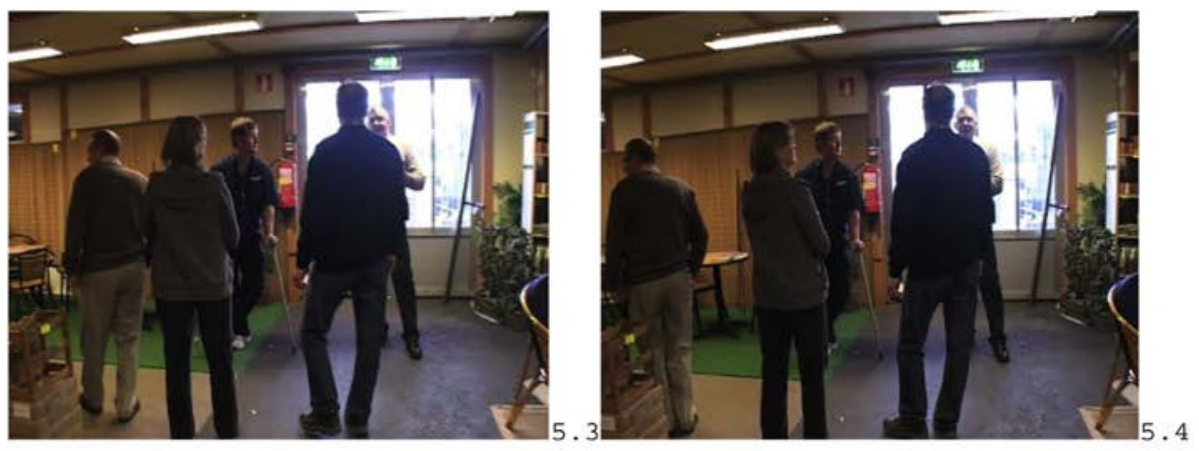

11 RIC

ja: : de man gö:r e ju de att man- (.) manyès what one does is PART that one, one,

(.) de förefaller ju: it seems PART 
As Richard begins to move on, there is, at first, a relatively long pause (7). However, Richard does not take two full steps before the energy auditor Conny, standing still and gazing steadily at Richard (Figures 5.2-5.4), takes a turn-at-talk (8). His turn is understandable early on as a continuation of the current sequence through the use of the final conjunction "så att" ("so [this means] that" [8]). It soon appears that his turn is a formulation of some consequence of his colleague's previous conclusions, which requires Richard's confirmation (10-11). The start of Conny's turn also comes off as rather urgent due to its quick beginning and the numerous restarts that are produced before a complete turn is finally achieved (8-9). The urgency shows an orientation to the fact that Richard, his main recipient, is already closing the sequence and walking away, thereby beginning to dissolve the current interactional space.

From its very beginning, Conny's turn is embodied as being addressed to Richard. Richard orients to this by stopping his movement and focusing his gaze on Conny again (line 8, Figures 5.3-5.4). Further, several restarts and hesitations delay the progression of Conny's turn until Richard reorients toward him. Having secured Richard as a recipient, Conny can continue the current sequence, with the entire group stopping, and thus maintaining the same interactional space as before.

The next excerpt, from the same corpus, also shows how walking away may be delayed by some explicit verbal linking-this time with a turn-initial "å"/"and". In contrast to the previous case, the participant delaying the projecteddeparture of the group is the speaker ending the explanation, rather than one of his recipients. Here, energy auditor Conny expands on his own explanation in a way that reestablishes the same interactional space as before (4).

(6) (Energy Analysis EA090402-2 34m44s-34m56s)

1 CON (0.3) kan du utnyttja à fả ut sjuttifemgradit vatten ur. you can use an' get seventy-five degree water out

2 (0.6) om du sätter en växlare på han.

if you put an intercooler on it

3 LEN $(0.4)$ ha: : ${ }^{\circ}$. yeah

4 CoN (0.2) då kan du blå:sa, då kan du blå:sa, (0.4) in de $i$ de hä:r.\# then you can blow that into this fig that into this \#fig.6.1

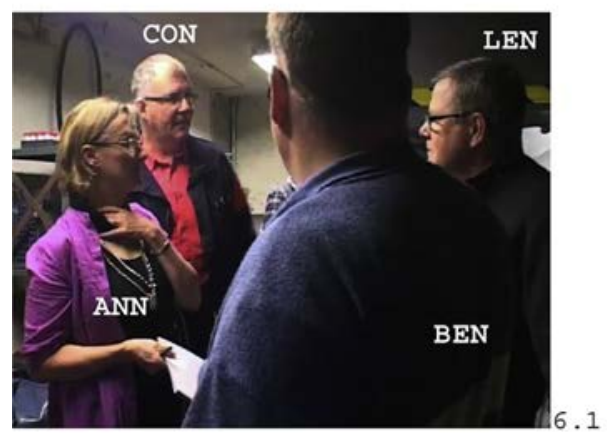

5 LEN $(0.4)+(0.3)+(1.4)+(0.1)$ ha:?

alright

len +turns left-->

6 LEN

(0.2) $a \%[: ?]$

alright

7 ANN $\%[(a)]$

$8 \mathrm{CON} \rightarrow \quad$ \%[>ả ] de+\#skulle du< göra+ oavsett, + and you would do that regardless of ann \%turns right, steps->

len - - + turns right+

fig \#fig.6.2 

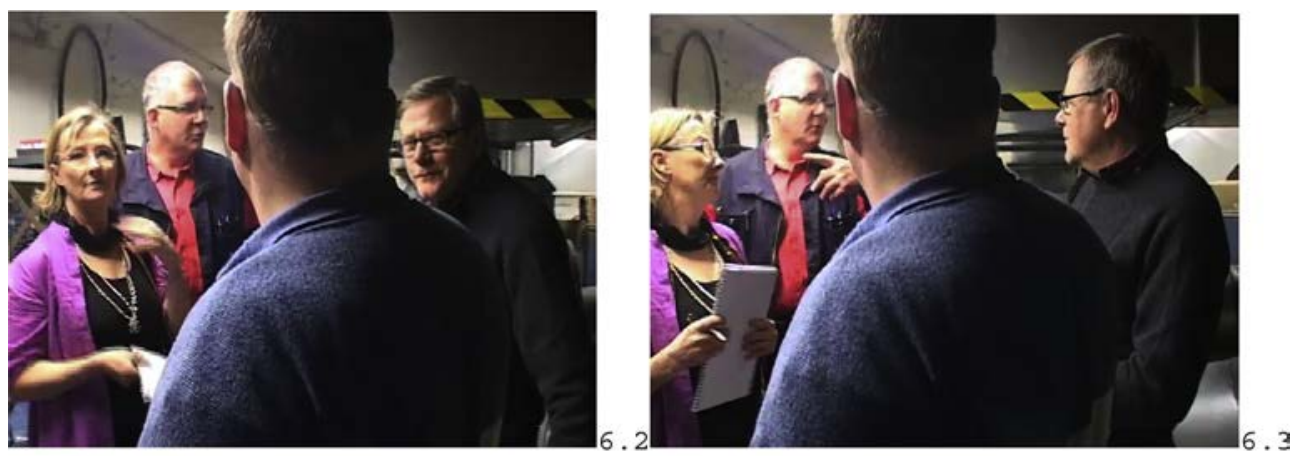
$9 \mathrm{CON}$
(0.4) pannan. \%för,
(0.3) kompressorn ¿\#
the boiler 'cause
the compressor
ann
->turns left back to the group--->>
fig
\#fig.6.3

Conny is ending a lengthy explanation of how Lennart, the owner of the small factory, could make his energy usage more efficient. Conny's turn is oriented to as being possibly complete by Lennart, as he twice produces a type of receipt token that arguably registers the explanation as newsworthy $(3,5)$. The second one is produced after a significant silence, as Lennart has just started to turn left, which projects walking away. Soon another of the energy analysts, Anna, begins to walk away, likewise producing a brief token to register the closing of the explanation sequence (7). At this precise point, however, Conny, who remains in a stationary position, expands his explanation by adding another clause using the coordinating conjunction "å"/"and" (8). His turn demonstrably accomplishes a re-orientation of his recipients toward the dissolving interactional space, and re-establishes it: they soon step back to their previous positions (8-9, figures 6.1-6.3).

In sum, participants may orient to the possible completion of the current course of action not only as being closingimplicative, but also as making walking away relevant. Whilst some participants may align with this projection and begin to step away, other participantsdeither the one who just completed the turn (Exc. 7), or its recipient (Exc. 5-6)dmay disalign by producing a new turn, prefaced by particles such as and and so, retrospectively building a continuity with previous talk, and implementing an action prolonging the previous activity, such as asking a question about a related topic. In both cases, the turn and action maintain and exploit the current interactional space, which is thereby not dissolved. As a consequence, the other participants stop as well.

\subsection{Initiating a new course of action at the same place}

As we have seen, actions that delay the mobile progression of the group may prevent the dissolution of the current interactional space, and momentarily postpone the closing of the current course of action, by adding more talk to it. Alternatively, delaying actions may be related to the initiation of a new course of action that continues to play out in the current location. Typically, this is the case when the new action refers to some aspect of the material surroundings in the same location. By initiating this type of delaying action, a participant initiates a new action that is locally anchored in the same environment and therefore affects the group's imminent departure. This type of action thereby reflexively accounts for its production and the necessity of a stationary position of the group.

For instance, a visitor can delay departure by asking a question about a local detail not yet mentioned: the issue is not just to stop the guide, but also to reorganize the interactional space, refocusing on that detail. While staying at the same place as before, the visitor establishes a new interactional space for a new sequence of actions, recruiting other participants to align with it. For doing so, local deixis and pointing are powerful resources.

A first instance of this phenomenon is found in excerpt 7, where the guiding participant, Ligour, is ending an explanation about how the greenery will be managed in a park. 
(7) (CAB_21e140613 - 1.02.50 lä)

1 LIG et qui à terme, (0.3) donneront une strate de chênes

2 *eu: :h .hh *euh: : qui s'installera.

eh: :m .hh ehm: : which will be put in place.

*turns fwd-*walks----->

$(0.6)$

3 LOU $\rightarrow{ }^{\circ} 1$ à vous avez *une* petite allée* (non;là) ?०*

oothere you have a small alley (no; there)?

lig

->*turns*pivots-----*stops---

voilà. y a là y a •une allée,

(0.2) qui passe ((cont.))

right. there's there there's an alley passing

- LH points--->>

As his turn comes to completion, Ligour bodily reorients and begins to walk (2). As he steps forward, Lourdet, one of the visitors, asks a question, beginning with "lä"/“there.” He responds by turning back toward her, pivoting entirely and stopping, so that at the end of the question, he is standing still. Shortly thereafter, he begins his explanation, which involves referring to the environment by pointing. Thus, the leading participant realigns his walking trajectory and stops, orienting to the emergent turn and answering the question.

Excerpt 8 offers a further case of delaying walking away by initiating a new sequence, establishing a new interactional space, while staying in the same place. As the guiding factory owner Lennart and a group of energy auditors arrive at a big, noisy welding hall (Figure 8.1), Lennart claims that there is nothing of interest there (3) and begins to walk on (Figure 8.2). However, Conny, one of the auditors, notices something (5).

(8) (Energy Analysis EA090402-1 41m57s-42m08s)
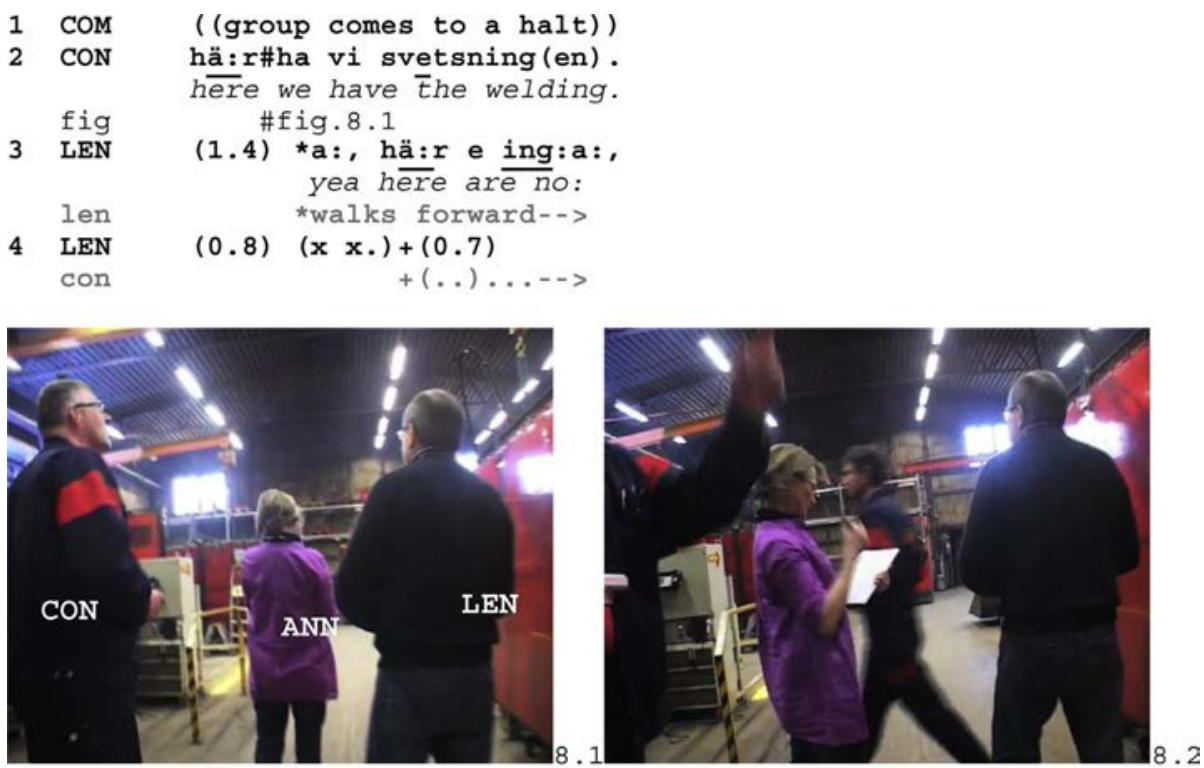

5 CON $\rightarrow$ \#de hä:r+ ä*väl\# (.) så: (.) att--

con this $\begin{aligned} \text { is PART So } \\ ->+ \text { points upwards-> }\end{aligned}$

len -->*turns around, looks up, stops-->

fig \#fig.8.2 \#fig.8.3

$6 \mathrm{CON} \rightarrow(0.4)$ \#där har*du pi:pan som eh+-- (.)

len

fig $-->+$ stroke left-->

\#fig. 8.4 

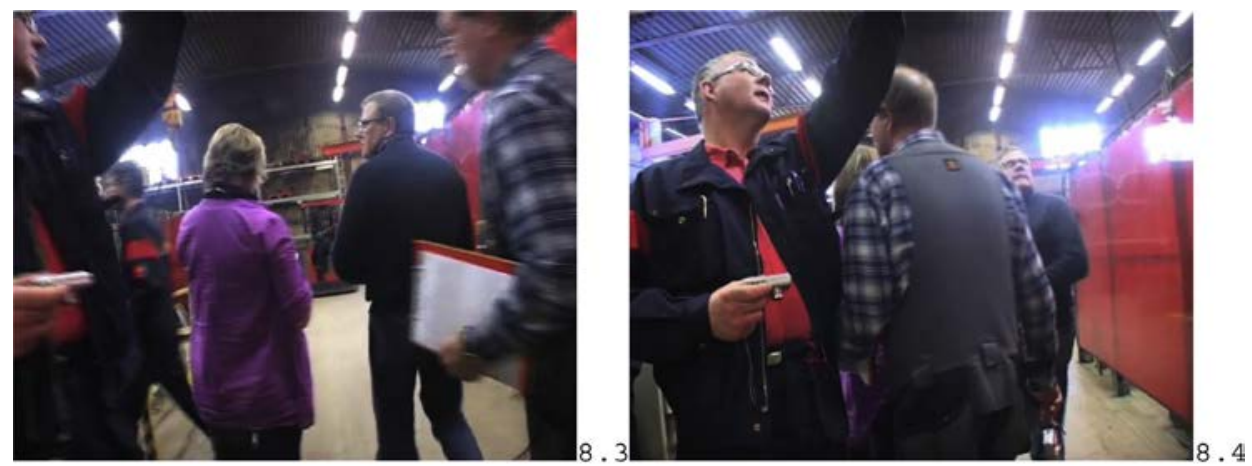

7 LEN a dä+:r komm+er alltså yes there comes then

con $\quad-->+$ points,,,$-+->$ 8 this air

$9 \mathrm{CON}$

con

[ (innanf] ör.)

(inside)

[jajämen],

that's right,

As Lennart begins to walk away (3, Figure 8.2), Conny initiates (4) what is to become a large pointing gesture toward something high up in the ceiling of the welding hall. The gesture's apex is coordinated with the completion of the demonstrative "de h€r"/“this" (5, Figures 8.2 and 8.3), which functions as the subject of the clause-try-marked by the epistemic particle "vlㅣ"- that follows. Hearing the beginning of Conny's turn, Lennart stops his forward movement and begins to turn around (5). Lennart's embodied reorientation is clearly monitored by Conny (Figure 8.3), who interrupts his turn in progress (5), and thereby gives Lennart time to turn around to see what Conny is referring to. When Conny restarts his aborted turn with a distant space deictic adverb ("df $\mathrm{r}$ "/"there") (6), Lennart is about to complete his reorientation and gazes in the direction of Conny's pointing gesture and gaze (Figure 8.4). So when Conny produces the first part of his turn, formulating what he has identified, he has established Lennart's visual attention within a new interactional space. Conny and Lennart agree about the pointed-at reference-the air coming through the pipe-and the sequence is closed (7-9).

In this example, two subsequent verbal deictic items are used, the pronoun "de h\&r"/"this" and the adverb "df्ar"/there," where the first one is marked for closeness and the second for distance. The initiation of a turn that begins with a deictic pronoun occasions that the participant who is walking away stops and turns around, to find the speaker making a pointing gesture that, together with the deictic adverb, accounts for the stopping action. We note that, whereas "de hør"/"this" is used for delaying the departure by a participant who has his back turned and who thereby cannot see what would be referred to, "d\&्r

Here referring to some aspect of the current place is a practice that orients to the slot that follows sequence closing as offering the last opportunity to introduce more talk relative to that place. As a consequence, it stops the incipient walking away.

\subsection{Initiating a sequence that is both retrospectively and prospectively oriented}

So far, we have seen how participants may either maintain the current interactional space to add further talk to a current course of action (x3.1), or initiate a new sequence of action, establishing a new interactional space within the current place, for instance, for the purpose of reference (x3.2). In both cases, these actions cause the group to remain stationary after the closing of the previous sequence, and after walking away has been initiated.

Participants may also orient both to the topical expansion of the current or immediately previous sequence, and to the establishment of a new focus of attention in the same material environment. Both aspects accumulate strong, accountable reasons to stop the group's projected departure. This is observable in the production of turns-at-talk that use both a turninitial particle such as and (seex3.1) and a deictic form (seex3.2): the former ties back to the previous sequence; the latter establishes a new interactional space, localized at the current place. Both have the effect of stopping the emergent walking away.

Such an instance can be found in the following extract, in which Navarro, an engineer guiding the inspection of a construction site, is finishing her answer (1-2) to a previous question by another participant, Gëomard, who thanks her for that (4). 
(9) (CAB_22_120713_VIS_ADPB_NAV_1-15-33)

1 NAV [c'est]: c'est les- $\mathbf{c}^{\prime}$ les voilà les

2 deux panneaux $l^{\prime}$ un à côté de l'autre

two boards one beside the other

3 nav $(0.3) *(0.3)$

4 GEO merci

$5 \quad$ thanks $10.1 \%$

geo $\quad(0.2)$ swithdraws->>

6 SUA $\rightarrow$ et +ces\# pierres, là* + ont été rapportées aussi\#, *ou and these rocks, there were also brought back, or +steps fwd---------+approaches NAV and points-> nav ->*turns back to SUA-----------*turns-> fig \#fig.9.1 fig.9.2\#

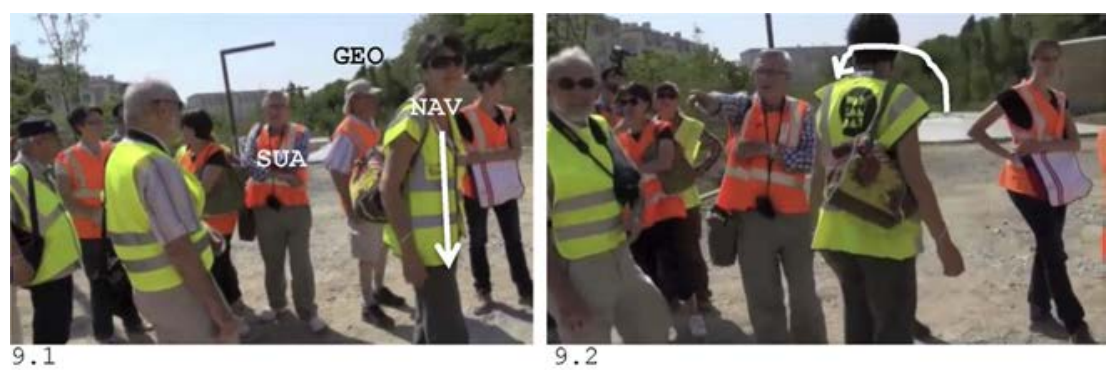

7 elles+ étaient sur le chantier* ${ }^{\circ} 1 a^{\circ}$.\# were they on the building site there. $->+$ stands and points--->

nav -twd the pointed at direction->*stops and looks->

fig \#fig.9.3

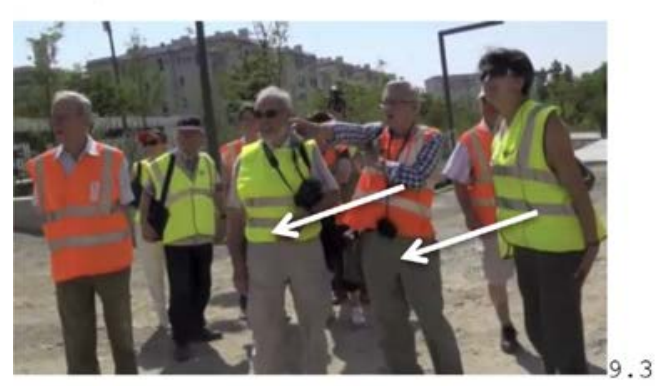

8

nav

NAV

10 SUA

11 NAV

12

13 NAV

14

15 SUA

16 NAV

17

$$
(0.9) *(0.2)
$$

$$
\text { là-bas? }
$$

over there?

ces [pierres (blantches là)]

these rocks (white there)

$$
-->+ \text { stands }->
$$

$$
\text { [c'est le: }
$$

(0.7)

$$
\text { it's the: }
$$

le le stock là-bas? c'est $\mathrm{p}$ - derrière le panneau perrier?

the the stock there? it's b-beside the board Perrier?

(0.3)

tnon:, >là< le mur qui est monté là. $\left[{ }^{\circ}(\text {. })^{\circ}\right]$

no there the wall that is erected there. ( )

+points----->

\section{[ah mais] le mur}

oh but the wall

il exi*stait, + tout ça exis[tait]

it existed, everything existed there $->*$ 
As Navarro has completed her answer (2), she pivots forward, orienting to the progressive direction of the visit. Gëomard disengages from the interaction with her (Figure 9.1). This moment is exploited by Suart in order to ask a question (6): as he is positioned behind Navarro and she is moving forward, he steps forward, approaching her, and points. She responds by pivoting back toward him (Figure 9.2) and then further re-orienting toward the detail he is pointing at, so that by the end of the question she is bodily aligned with him. Other participants align as well (Figure 9.3). Furthermore, Navarro points in the same direction, in a repair sequence about the referent of the deictic "lä-bas"/"over there" (9-15).

By "et"/“and"-prefacing his question, as well as by using the word "aussi"/"also" (6), Suart establishes a link backwards to the previous discussion, and constitutes his question as part of the ongoing activity and task (Heritage and Sorjonen, 1994). Furthermore, by using a double deictic ("ces pierres lä"/“these stones there" 6) as well as a final "lä-bas"/“over there" (7), he formats his question in such a way that the answer depends on the orientation toward, and recognition of, the pointed-at detail. This contributes to the stopping and realignment of Navarro, which is further fostered by the repair sequence, consolidating the joint attention on the referent.

This format - turn-initial "et"/“and" and turn-final "lä"/“there"- is recurrent in the French data. Here is a similar instance from another corpus. Luc, the guide, completes his explanation of a bulletin board abandoned in the garden (1-2). On the final outbreath, he steps forward, and takes another step, while his recipient, Jean, offers an assessment of the object, to which Luc responds with a closing implicative "voilä" (4). Even if the latter is expanded with an unfinished turn, Luc's embodied initiation of the closing is clearly visible.

(10) (archijardivis no2 - 00.03 .02 berse)

\section{LUC}

Hhh. non on a mis ça, parce que ça peut servir à

2 Hhh. no we have put this, because it can be useful as

$l^{\prime}$ affichage des fois. *h

a billboard sometimes $h$

luc $\quad * 1$ step fwd->

3 JEA

non, mais c'est amusant.

no, but it's funny

4 LUC

(.) voi*là, oui c'est:=

right, yes it's:

$->* 1$ step fwd-->

5 JEA $\rightarrow$ =+et ta* ber*set elle est [où là.]+

and your hogweed where is it, there?

6 LUC

jea

luc

7 JEA

+points fwd---+gesticulates------+points-->

->* *upper body turns back->

c'est *1 [ à?

it's there?

8 LUC

[ 1 à,

there

luc

$->*$ comes back and walks towards the plant-->

9 LUC

(.) c'est ça+ la berse. >alors< la berse c'est ((cont.))

that's it the hogweed. >so< the hogweed is ((cont.))

$->+$

As Luc is audibly and visibly ending his explanation (although his turn is left unfinished, he uses the closing particle "voilä" and steps forward), Jean asks a question, with an "et"/"and"-initial and a "lä"/"there"-final particle, pointing to a plant ("berse"/"hogweed"). This question is disconnected from the previous topic and addresses a referent that is located close by. The question delays the progressivity of the walk, since Luc comes back and reorients his trajectory, now walking toward the plant. At this point, the hogweed is established as a new topic. It is interesting that this turn, which is initiating a new sequence and introducing a new topic, is "and"-prefaced: this shows that even when there is no obvious link to a just previous action, this tying-format can be used as a formal resource to warrant the legitimacy of the stopping move.

Such retrospective-prospective cases can also be found in the Swedish data. In the following extract, Lars and Mats are leading a group of energy auditors through a local furniture store: 


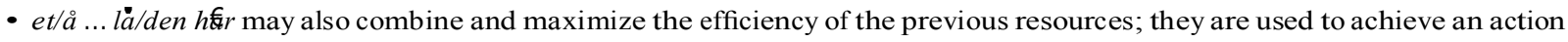
that is both a continuation and an addition to the previou s course of action, which also stops the incipient walking away $(\S 3.3)$.

4. Responses to actions that delay progressivity

The consequentiality and efficiency of actions that delay the progressivity of the activity is observable in the responses of the co-participants, who can actually stop, step back, and realign with the previous interactional space, bodily reorient within the same material environment, or modify their mobile trajectories in a more or less (dis)aligning way. While walking away is a practice that manifests (and reflexively contributes to) sequence and activity phase closing, stopping, slowing down, turning around, coming back, etc. constitute a family of practices that bodily manifest a response to actions-in our case, embodied turns-at-talk-that delay the progressivity of mobile activities. In this sense, walking away versus stopping, and its dynamic variations, are practices that make visible and publicly intelligible the emergent organization of actions building the mobile versus stationary phases of an activity.

\subsection{Stopping}

Delaying actions such as questions, comments, noticings, requests for confirmation, etc., systematically have a first effect on the trajectory of the participant stepping away: whereas s/he was generally initiating walking away before the verbal completion of the previous turn or sequence, this participant also generally stops before the completion of the delaying turn. For instance, in Exc. 4, the gardener stops at the end of the second question (10); in Exc. 5, Richard stops during Conny's request for confirmation (8); in Exc. 7, the architect stops toward the completion of the question (3); in Exc. 6, the leading participant, Lennart, stops in the middle of Conny's question (8-9), as is the case in Exc. 8 (5); in Exc. 9, the guide stops toward the end of the question (7); in Exc. 10, the gardener turns back in the middle of the question and comes back on the next turn; in Exc. 11, the question brings the group back to a stationary position. In all of the excerpts, the post-walking-away delaying turns studied have the effect of stopping the participant who initiated the walking.

Moreover, the delaying turn also modifies the movement and bodily orientation of the other co-participants. When this turn emerges, some of them may have already aligned with the walking away, while others may still be stationary. Upon hearing the turn, they may either realign or continue their trajectories, but often slow down or even stop.

These aligning and realigning movements can be observed in the next few extracts. In the first one, a group of visitors is observing the foundations of an aerial walkway above a garden (Figure 12.1). The guiding architect, Ligour, explains that within a few years the greenery will make these foundations invisible (1-2):

(12) $(\mathrm{CAB} 21-140613$ e 1.05 .00$)$

1 LIG

2

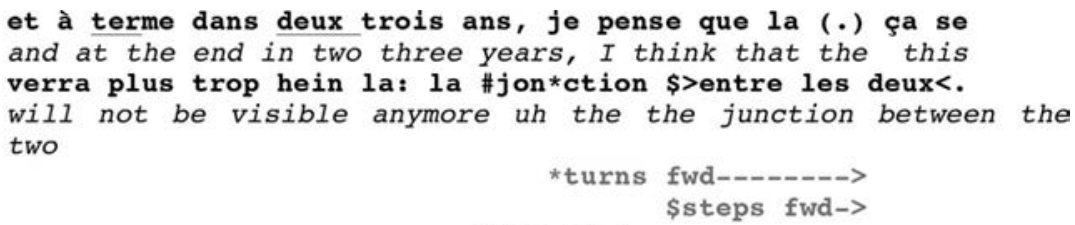

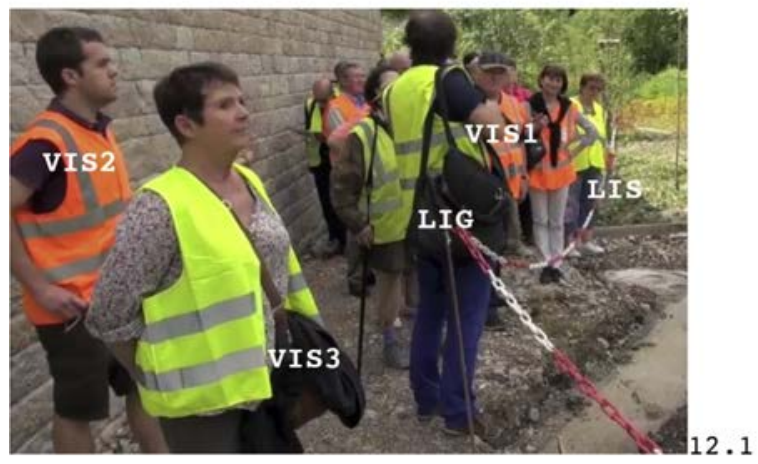

3

$£(0.2)$

vis2 fmoves fwd->

4 AUB

${ }^{\circ}$ ah bon ${ }^{\circ 0}$ *

${ }^{\circ}$ yes well ${ }^{\circ \circ}$

lig -->*walks---> 

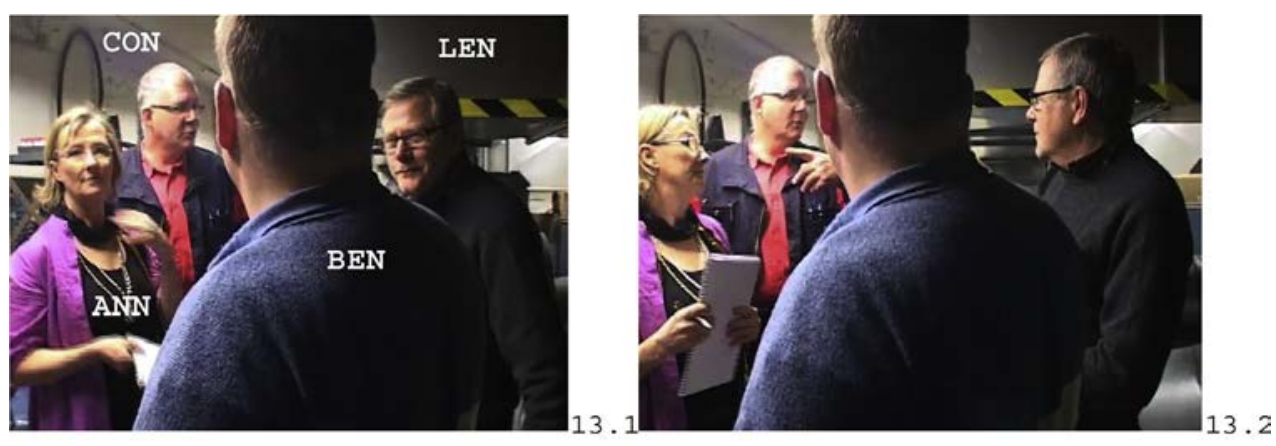

9 CON (0.4) pannan. \%för, (0.3) kompressorn ¿\# the boiler 'cause the compressor

ann - - sturns left back to the group->>

fig

$\#$ fig.13.2

In this case, Lennart, the factory owner guiding the group of energy auditors, initiates closing of an explanation sequence by beginning to move away and by producing a short sequence closing verbal news receipt (5). Conny makes a rushed expansion (8), gazing at him (Figure 13.1), and Lennart turns back to reinvest the same interactional space as before (8, Figure 13.2). Although not directly addressed, Anna likewise returns to her previous position within the group (9).

These stopping and realigning movements demonstrate how delaying actions e a question and a turn expansion in the excerpts above e shape the organization of collective movements that responsively align or disalign with them.

\subsection{Returning}

A second way to respond to delaying actions is to return to the location that one is about to leave, or has already left. Such responses are typically produced after a turn that includes a deictic reference to the local environment. Below, we offer two examples of returning, showing how this practice may be initiated at different moments during the emergent walking away.

Our first example in this section shows how returning is already initiated as the participant walking away takes his very first step, by transforming this step into a pivoting full $180^{\circ}$ turn, which positions himself as a recipient of a claim involving deictic reference. At the beginning of the excerpt, recorded at a car-testing station in Sweden, walking away is already projected, and all members of the group are taking small steps and looking around. In this half-stationary, half-mobile environment, energy auditor Conny is assessing, gazing at Jan-Åke (Figure 14.1), a certain type of old electrical units. When his turn-at-talk reaches its projectable completion (3), his colleague Anna orients to this as making walking away relevant: she turns forward and begins walking (3), and soon Conny himself does the same (5):

(14) (EA090331-2 34m29s-34m41s)

1 CON

2

3

$4 \begin{aligned} & \text { ann } \\ & \mathrm{J}-\AA ̊\end{aligned}$ du (.) dom- dom här gamla aggregaten dom ä: ä: ä: hey the these old units they are are are

(.) ä så b- (.) ålderdomlia= are so b- old-fashioned

$=s a ̊$ dom ligge?på noll fem\&(ti).

so they are at zero fif(ty)

otturns head left-->

\&turns, takes step forward-->

(•)\#(ja:)\%

(yes)

$-->\%$

\#fig. 14.1

$+($ )-

+turns left, steps right foot--> 
A further case shows a return at a significantly later stage in the trajectory of the participant walking away. Here, Jean, who is guiding a group of architects through a building, has finished an explanation concerning a series of courtyards (1-2) and has already walked a long way when one of the visitors, Yan, asks him a question about a patio (4-5) that can only be seen from the window where he is staying (Figure 15.1). As in the previous extract, Yan's comment refers to an object in the material surroundings.

(15) (Archivis 01_53.14] [A2_46.36]) (frmWAII,e12,MC)

1 JEA \#et après *'c'est bâtim- bureaux administratifs ${ }^{\circ}$ et and then these are administrative build- offices ond

jea

fig \#fig.15.1

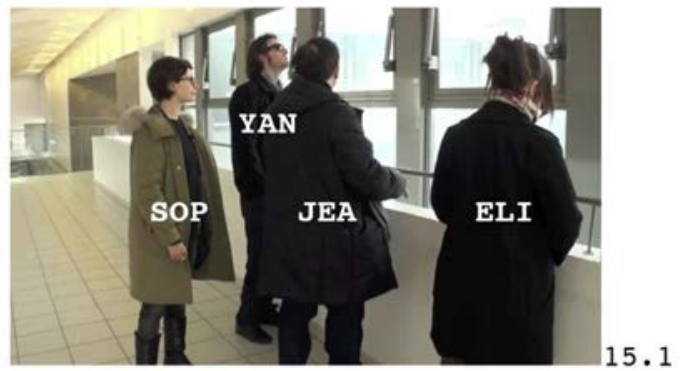

les sa*11|es* de| $\neq$ cours $^{\circ}$

(the) lecture rooms ${ }^{\circ}$

jea

$-->* . . . *^{*}$ walks forward-->>

‡walks forward-->>

cam

3

$(2.0) \#(1.0)$

|... . moves backwards-->

fig \#fig.15.2

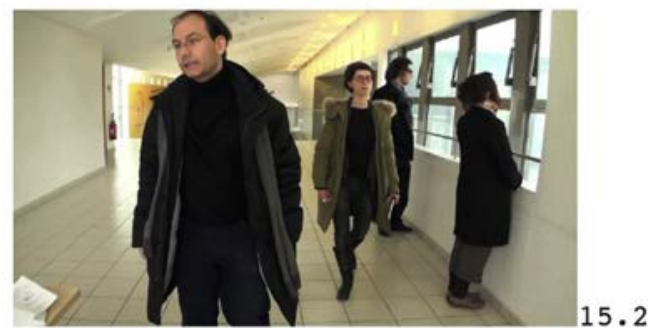

4 YAN talors c'est marrtant parce qu'en *fait ils sont

so it's funny because actually they are

yan tturns toward JEA+two steps forwards-->

5

jea

$--->*$ turns back->

\#ab‡solument\# pas* uti|lisés, * hein+\# les:

absolutely not used, PRT the:

yan

sop

jea

cam

fig

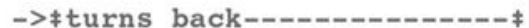

$->*$ comes back-->>

$-->+$

$-->\mid$ moves forward-->>

\#fig.15.3 \#fig.15.4

\#fig.15.5 

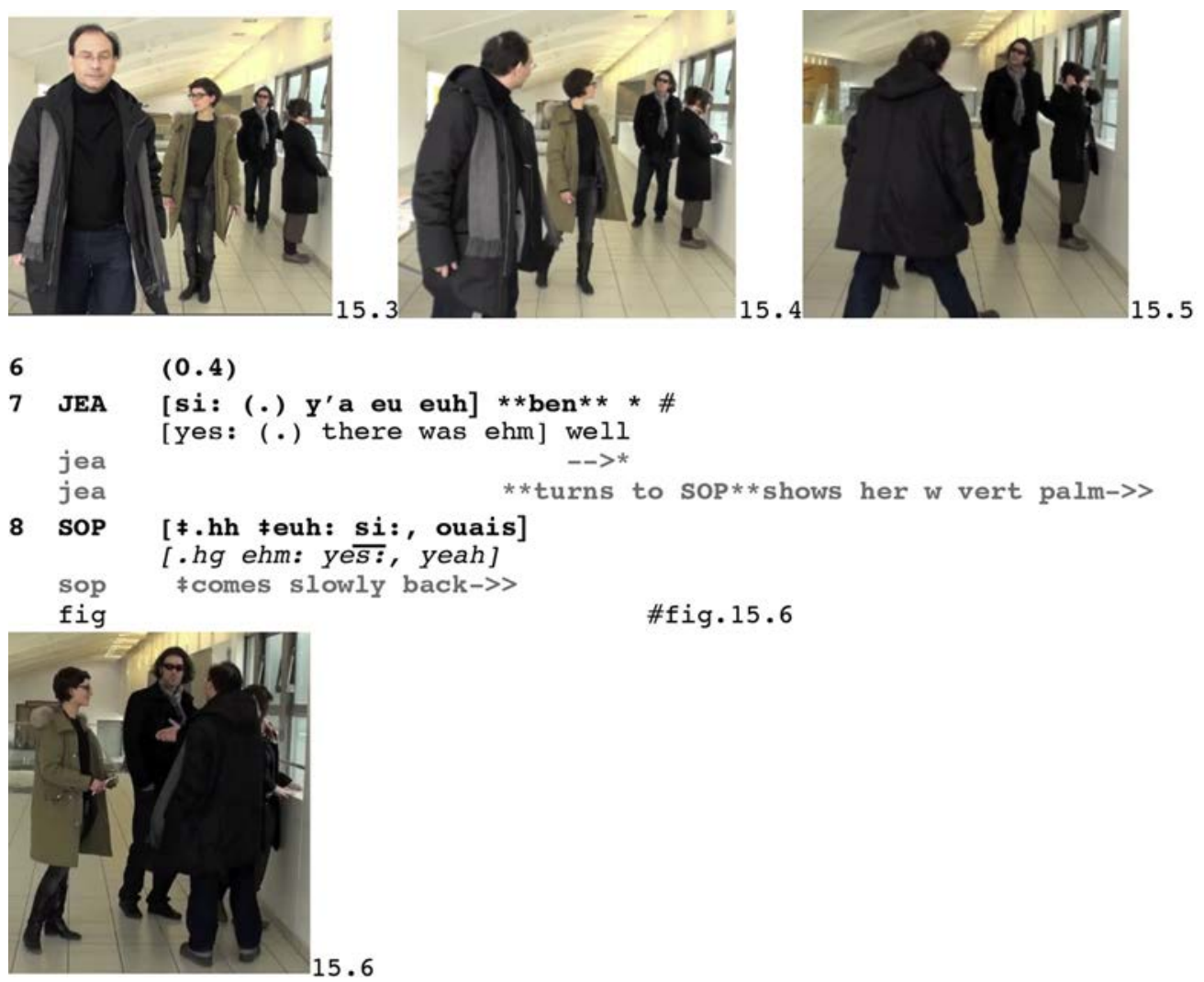

\#fig.15.6

As Jean completes his explanation, he walks away (1-2), and Sophie follows him (2). However, Yan and Elise remain still, and continue to look through the window at the patio that is visible from there (Figure 15.2). After a long silence (3), Yan produces a request for confirmation: as he initiates it, he turns his head toward Jean, who is already walking away, and takes a few steps toward him. The object of Yan's inquiry is referred to using a pronoun ("ils"/“them") as part of a projected, but never actually completed, left-dislocated turn construction; Yan is also using his left arm to gesturally refer to something outside the window (partly visible in Figure 15.3). This multimodal turn is responded to by Jean stopping and turning back (Figures 15.3-4). Moreover, before Yan's question is complete, Jean begins to walk back relatively quickly toward Yan, who is still by the window (Figure 15.5). Sophie returns too, although more slowly.

Jean and Sophie now both provide an answer (7e8) to Yan's question, and Jean points at her, selecting her for the development of an extended explanation. At this point, the previous stationary interactional space is re-established (Figure 15.6).

Our last two excerpts have shown two fairly different forms of returning: a pivoting "twirl" on the first step versus walking back from a distance. These were produced following two different turns-at-talk that both included some deictic reference. A turn with deictic reference demonstrably makes the recipient's public attention conditionally relevant. The embodied returning response is contingent on how far the participant has gone while walking away, as well as on the visual availability (with regard to both distance and perspective) of the referred-to object.

\subsection{Moving forward while turning back}

The mobile activities studied heredavariety of guided visitsdare characterized by a double imperative. On the one hand, there is an orientation to actions and occasions to participate that are bound to a particular place in a stationary position. On the other hand, there is an orientation toward the progressivity of the overall activity of the visit. This produces a tension between staying and moving on, and the necessity to coordinate joint departures from momentary stationary activities. This tension was formulated in so many words in the complex instructions given by the guides in Excerpts 2 and 3, offering the opportunity to ask questions, but also warning that questions might delay the visit too much. This tension is also observable in the embodied way that participants deal with both the projections related to the forward movement, and the conditional relevance of delaying questions and other actions that project a response within the current stationary interactional space or the same material environment.

In this section, we focus on practices that address these opposed principles: participants might respond verbally while continuing to walk, or adopt a mobile body torque that enables them to both walk forward and turn back to the person performing the delaying action. 
In the next fragment, from a touristic visit in Lyon, the guide, Hilaire, is explaining that the current neighborhood is characterized by many cloisters and that consequently most street names have a religious connotation.

(16) (tourly1_10_46_saint-charles)

1 HIL et *on a* la rue de $l^{\prime}$ annon*ciade par exempl*e, $(0.4)$ and we have the annunciation street for instance $(0.4)$ $>$ pts*, , *.............. points---------*palm open->

2 hein, ça* c'est des mots, *(0.3) ( $\left.d^{\prime}\right)$ anciens *cou\#vents, uh, these are words, (0.3) (from) old convents, $->* 2 \mathrm{H}$ as bowl-------*holds-------------*2H beat gest->

fig \#fig.16.1

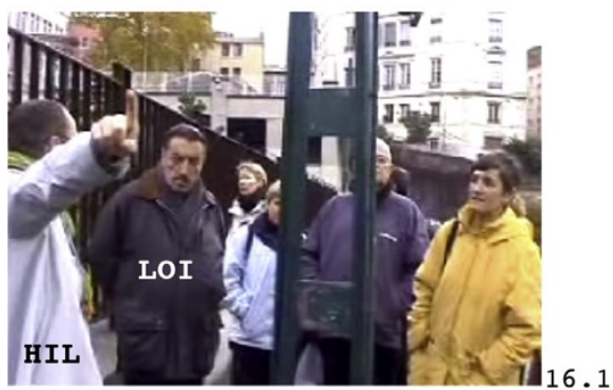

les annon+ciades, >*les carmélites, 'etcaetera

the order of annunciation, the carmelites, etcetera *1 step fwd-->

4

cam

+ moves aside-->

etcaetera ${ }^{\circ}{ }^{\circ 0}$ etcaetera ${ }^{\circ \circ},<\#$

$->*$ walks forward-->

fig

\#fig.16.2
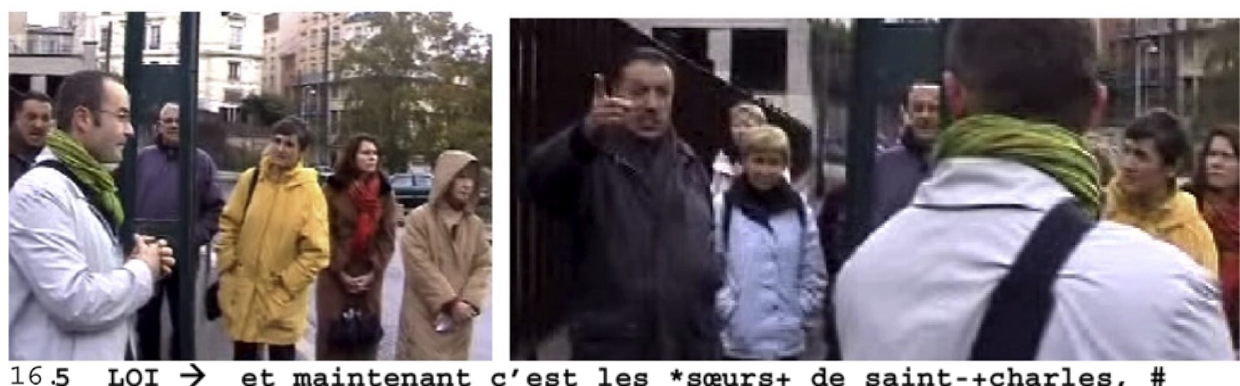

and now it's the sisters of Saint-Charles

hil

-->*turns back--->

cam

$->+$ turns back+

fig

$(0.4)$

fig.16.3\#

7 HIL voi:*là.*

that'sit.

$->*$ big nod*

8 LOI $\rightarrow$ *dont l'fondat*eur est né à bourg,

of which the founder was born in Bourg,

hil *walks forward*turns back ((then not visible anymore))

group

9

$(0.2)$

|begins to walk-->>

10 HIL à bourg, (.) ouais.

in Bourg (.) yeah.

$(0.7)$

12 LOI $\rightarrow$ alors. ${ }^{\circ}$ et il a il a donné le nom de: (0.4)

'SO. ${ }^{\circ}$ and he has he gave the name of $(0.4)$

des sœurs de saint-charles parce qu'il avait

Saint-Charles sisters because he had

une grande admiration:, (0.4) pour saint

a great admiration (0.4) for Saint

Charles of Borromeo 
Hilaire explains the street names by pointing at different places within the environment; he gives a list of ex- amples, accompanied with co-speech baton gestures. The body postures of the participants are aligned with these actions, Hilaire gesticulates toward the group, and the group is looking at him, in a face-to-face frontal way (Figure 16.1).

He comes to sequence completion: as he names the second listed item, he takes a step forward, projecting the closing of his explanation; the third item is a generic "et cetera," repeated with decreasing voice, and he begins to walk forward as his voice lowers (Figure 16.2). The camera recording the interaction immediately adjusts to this movement, projecting imminent walking away; the audience does so too, and begins to follow the guide.

In this sequential position, an action postponing the ongoing closing is possible. Instead of taking this opportunity to initiate a question, Loïc self-selects and exploits it for another type of action (5), offering a turn-continuation ("et maintenant c'est les sœurs de Saint-Charles"/“and now it's the sisters of Saint Charles" [5]). This and-prefaced turn retrospectively ties the turn both to the previous one and to the ongoing activity, occasioning a reorientation of the participants-the guide turns back, as does the camera, and the other participants look at Loïc (Figure 16.3). What Loïc does is to extend the guide's turn and action, providing more information, while pointing just like the guide was doing before. He displays his epistemic authority and performs a typical "guide-" (and not "guided-") category-bound activity (Sacks, 1972; De Stefani and Mondada, 2017) ina descriptive turn.

Hilaire's subsequent action (7) responsively aligns with Loïc's contribution. In this sequential position, Hilaire does not display any superior epistemic authority; rather, he closes the sequence again and walks forward (beginning of line 8). At that point, Loïc produces a new extension, a delayed completion of his previous turn (8), again occasioning Hilaire's turning back and responsive action (a repeat of Loïc's turn followed by "ouais"/“yeah”, 10). After a pause, as the group continues to walk, Loïc goes on (12), adding more information about the nuns' name. Again, Hilaire does a repeat, partially overlapping the pre-completion of this turn (16), and turns back while continuing to walk forward.

Loïc's extension of the guide's explanation shows how a "guided" participant can produce actions that compete with those of the "guide." The fact that the guide continues to walk away, and with him the group, is a way of defending a categorybound activity typical of the guide (De Stefani and Mondada, 2017), namely, the management of the group and the direction of the bodies in the guided visit.

The next case similarly shows how a participant may embody an orientation to the relevance of walking away, following an invitation by a member of the group to move on, but also of staying, as he is being constituted as a recipient of a turnat-talk by another member within the current stationary interactional space. Mats, the owner of a small business that he is showing to a group of energy auditors, is finishing an explanation of what a store much bigger than his could be like (13):

(17) (EA090401-1 46m48s-46m58s)

1 MAT
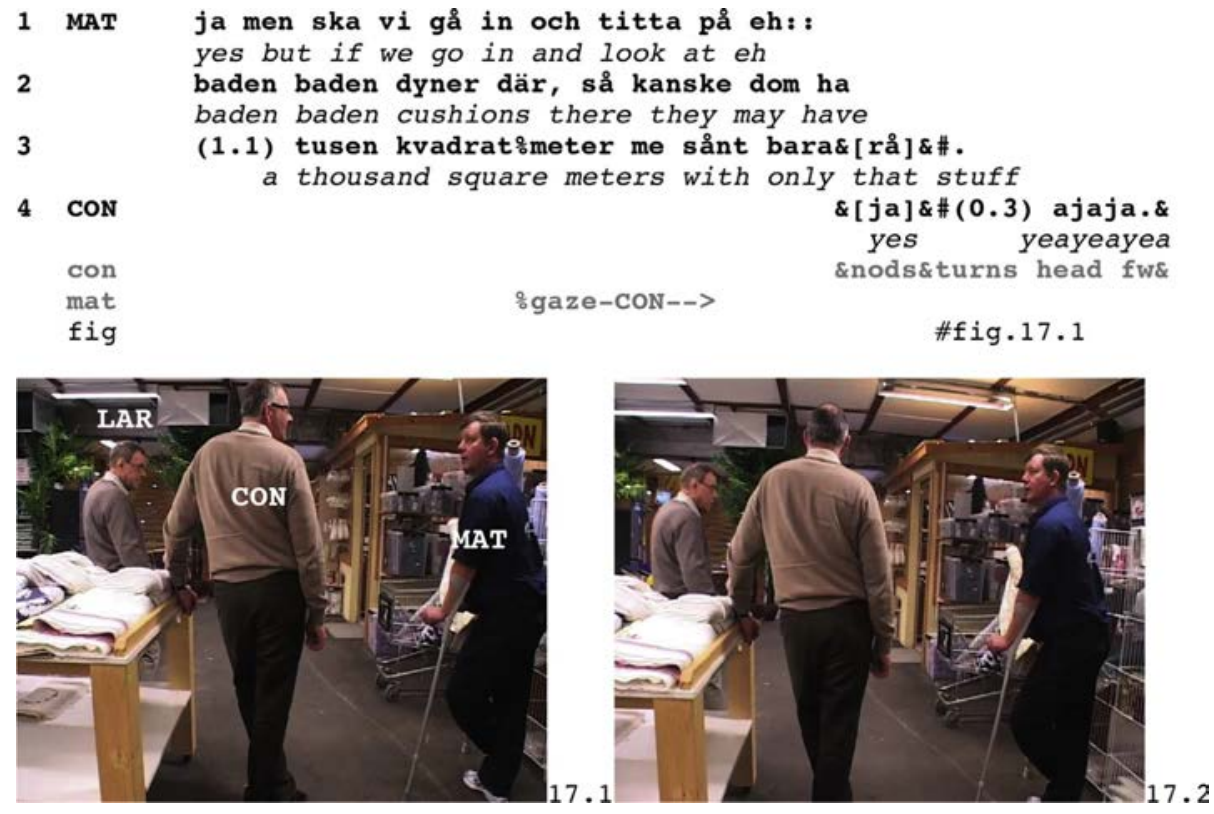
fig \#fig.17.2

6 LAR

+[ ska vi knalla \&vidare då.]\%

shall we move on then

7 MAT $\rightarrow$ +[(du vet) liksom\&de gå'nte ] $\%$ å ta å:\&t se av\#nån[ting.]\&\&\#

(you know) sort of it's not possible to care about anything

$8 \mathrm{CON} \rightarrow$

[nä:j, ]\& \#\#

no
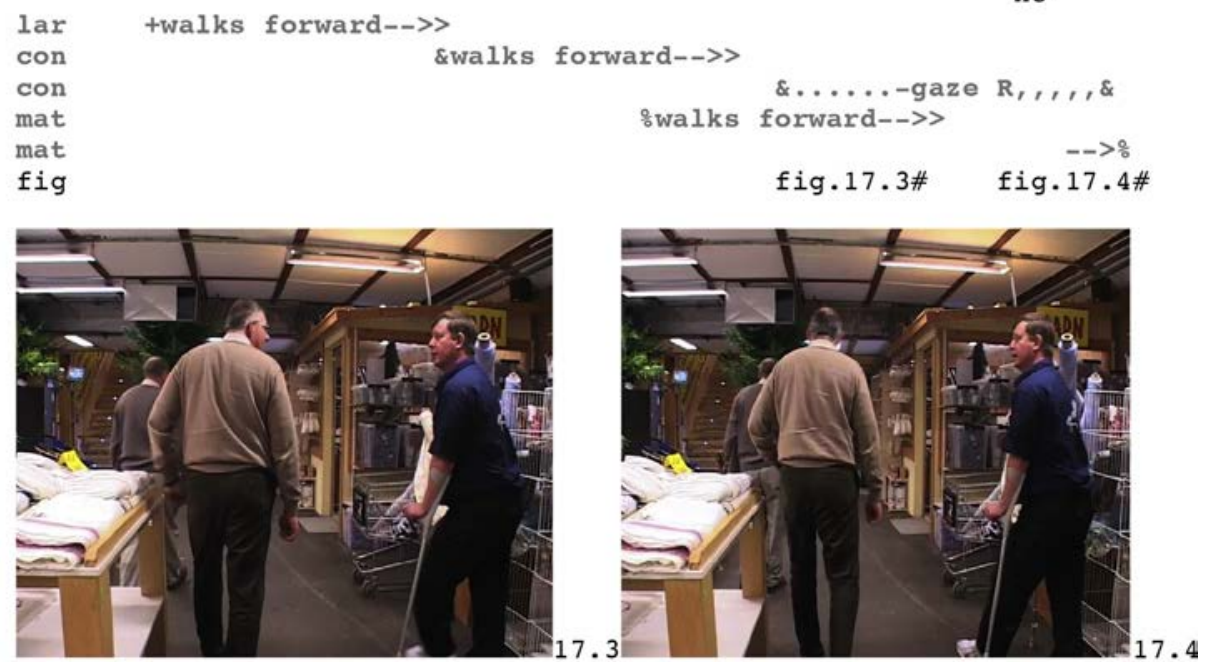

9 MAT

$$
\begin{aligned}
& \text { (.) [dä e ju: : ] } \\
& \text { it's PART } \\
& {\left[\begin{array}{l}
\text { nä:j. } \\
\text { no }
\end{array}\right.}
\end{aligned}
$$

When Mats' explanation comes to a recognizable possible completion (3), Conny, one of the energy auditors, expresses agreement through a series of affirmative response tokens (4). As Conny is simultaneously also turning his head away from Mats, he disengages from a position as recipient and thereby embodies the explanation sequence as closed (4; Figures 17.1 and 17.2). By turning forward, he also faces the direction of the projected future movement of the group. That Conny treats the sequence as closed is registered by Lars, who, after only a short pause, explicitly proposes that the group move on (6). However, the moment Lars begins his turn, Mats, completely overlapping Lars, continues his previous explanation. Mats still addresses Conny, as evidenced by his continued gaze toward him (04-08). Mats' turn expansion is a kind of post-final assessment, which makes relevant an agreeing response by Conny (07-08). This means that Conny is being addressed by two participants, each of whom projects a particular next action by Conny: Lars invites him to resume walking, and Mats projects an agreeing response to his assessment.

Conny'sembodied action demonstrates his accountable participation in both courses of action. Byactually resumingwalking, he accepts Lars' invitation. But as he does this, he also quickly turns his head toward Mats (Figure 17.3) and produces a brief agreeing response at the next possible completion place (7-8). Thereby, he manages to position himself as a recipient of Mats' turn, even while he is actually walking away from him. As Conny - Mats' primary recipient - begins to walk away, Mats also begins to move on, so that at the end of the sequence, both of them are walking (8; Figure 17.4). At this point, Mats begins a further expansion of his turn, which however is overlapped by two reiterations of Conny's prior response and subsequently abandoned (9-10). Having come thus far, walking away has taken precedence over continuing the previous verbal course of action.

These extracts show how a delaying action (by the guide in Extract 16 and the guided in Extract 17) may be confronted with a double pressure: on the one hand, the progressivity of the visit; on the other hand, a normatively expected response. This corresponds to a double orientation, both backward to the previous sequence, and forward to the next one. This double orientation is often embodied in two exclusive movements, stopping versus walking away. However, it can also be embodied in a unique, complex posture, constituting a mobile body torque (Mondada, 2018b, referring to Schegloff, 1998), which consists of walking forward while at the same time turning backwards. Conny's quick lateral head turn as he has just started to walk in Extract 17 (line 8, Figure 17.3) may be considered an example of this posture.

An much more developed occurrence of the mobile body torque is visible in the next excerpt. We join the action as the guide is explaining the diversity of plants that will be grown in the park $(1-4)$. 
1 GUI mais tout c'qui est viva:ces, (0.5) euh mul:ch:, travail

but everything that is perennial ehm mulch,

2 d'paillage au sol, n'a pas encore été euh réalisé. (.) ts straw-mulching, has not yet been realized.

.hh ben on va s'avancer un tout petit peu, ça vous .hh well we'll move on a little bit, this will

4 donnera *une idée, \# et pis après on $r^{\prime}$ fera $d^{\prime} m i$ [tour

5 VIS give us an idea, and then after we'll come [back

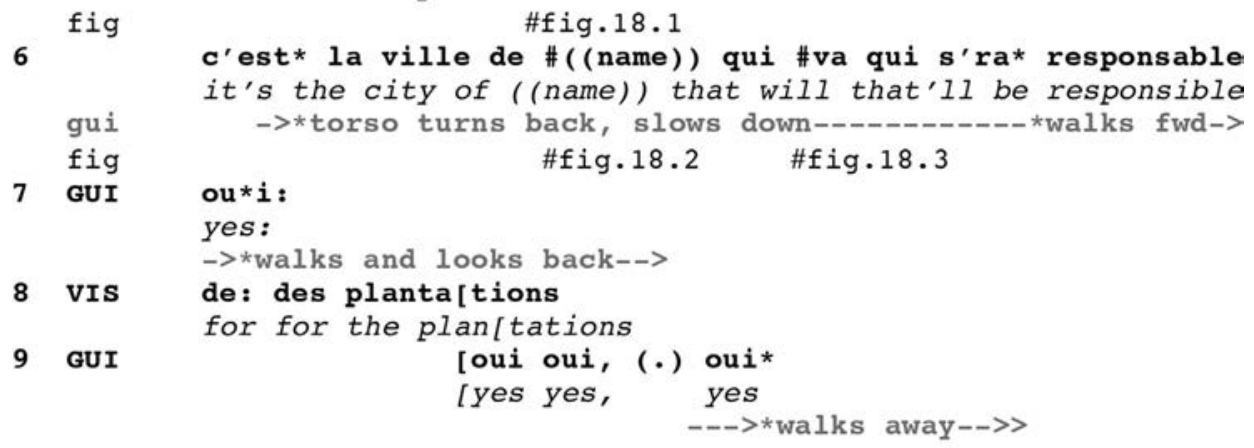

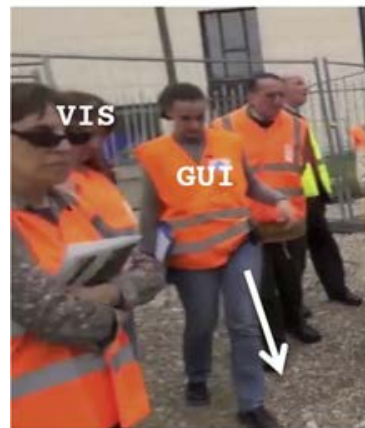

18.1

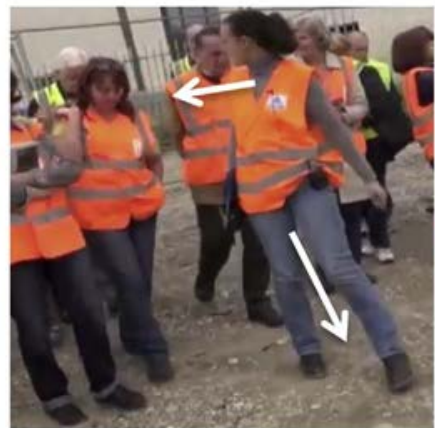

18.2

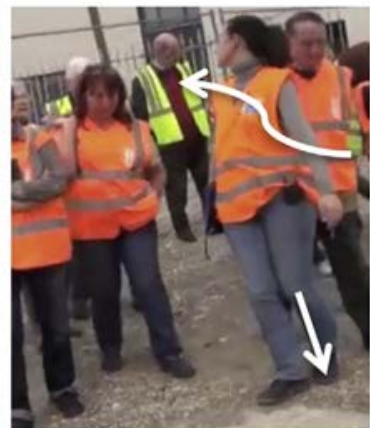

18.3

The guide completes her explanation at a transition relevance point that is minimized by a continuation (3-4), in which she invites her group to move forward, while she herself begins to walk (4, Figure 18.1), an action which clearly favors progressivity. A participant asks a question-making a request for confirmation-in overlap with the final word of the guide's turn (5-6). The answer is minimal: some affirmative tokens merely confirm what the visitor is asking. Requests for confirmation constitute a format that orients to, and makes expectable, a rather brief response (Mondada, 2018b), which minimizes stops and other delays. In a mobile context, as here, it favors the incipient mobility and progressivity. The way the guide formats her answer bodily shows a mobile body torque (Figures 19.2-3): during the question, she slows down but does not stop; she turns back, first with just her head (Figure 18.2), then the torso (Figure 18.3), while continuing to walk. In this way, the upper part of her body orients back toward the questioner, and the lower part forward toward the progressivity of the visit.

This excerpt shows that the answer can be given either while stopping, giving full attention to the questioner and addressing the entire group, or while walking, favoring the progressivity of the visit, minimizing the length of the answer and addressing only the questioner. A practice like the mobile body torque combines both orientations, toward the delaying action and toward the progression of the visit.

\section{Discussion and conclusions}

This paper has offered a follow-up to the systematic analysis of the practice of "walking away" proposed by Broth and Mondada (2013). This second study further examines methodic embodied practices that can manifest and respond to the projections of walking away, and stop or disturb their trajectories. 
In line with Heritage's (2011: 211-212) discussion of practices in turns-at-talk, we describe an "embodied practice" as some embodied behavior having three characteristics: 1) it has a recognizable form; 2) it is produced in and for a particular position in a turn or sequence, and as part of some multimodal and contextual gestalt; 3 ) it constitutes some action. "Walking away" is a generic embodied practice available to participants for initiating, negotiating, and managing closings in an efficient and visible way. Guided visits represent an exemplary activity in which this practice is observable, since this activity is characterized by a guide leading a group from one location to another, moving to the next place when the previous has been exhaustively shown, explored, and explained. However, the practice is clearly not restricted to this kind of setting, but is readily observable in a wide range of ordinary activities.

In our first study, we demonstrated how the projection and trajectory of walking away are designed and achieved (Broth and Mondada, 2013). In this follow-up paper, we have shown how these trajectories can also be slowed down, discontinued and stopped. Because they have a routine character, and because they are visible and accountable, trajectories of walking away are also highly projectable-and can thus be intercepted, deviated, and stopped. This paper has offered a systematic description of actions doing so, which we have called "delaying actions."

Delaying actions are responded to by stopping or slowing down a projected movement. They represent an efficient way to reshape an emergent sequential trajectory, both from an organizational and a normative perspective. Stopping does not only affect and change the organization of an ongoing action; it also concerns the normative expectations, rights, and obligations related to this action. Delaying actions that have the effect of stopping the incipient moving away orient to fundamental features of action progressivity - conceived here both in an abstract, temporal way, and in a literal, embodied, and stepwise way (progredi in Latin means "to walk forward").

Our analysis has followed the sequential organization of these trajectories by examining the completion of a sequence or a more extended stationary course of action, the projection of walking away, the timely production of a delaying action, and the responsive modification of the projected action. In the remainder of this conclusion, we briefly comment on the temporality of these actions, the accountability of delaying actions, and their efficiency in modifying a projected trajectory.

Given that closing and moving away in mobile settings are projectable, often explicitly announced as such, and highly visible, participants may orient to the first opportunity to modify their trajectory. There is a pressure for early delaying actions to abort walking away, even before walking is actually initiated: once the progressive transition to a next activity has been initiated and the participants have been engaging in it, it is increasingly difficult to efficiently hinder its emergence and trajectory. This is particularly the case for actions involving larger groups of participants, which necessitate considerable coordinating efforts to be moved and stopped. It is also particularly the case for actions that exploit the existing interactional space and participation framework-for example, asking questions publicly (rather than privately) supposes the static permanence of the audience as a group (Mondada, 2017). While early initiated delaying actions often immediately stop walking away, delaying actions can also happen later, when part or all of the participants might have already begun to walk away, consolidating their mobile trajectory. The later the delaying action is initiated, the more difficult it is to actually stop the ongoing movement.

More particularly, these trajectories are shaped by the formatting of the delaying action and the corresponding embodied response. Our analysis has shown that delaying actions display an orientation to their accountability - both in terms of their intelligibility and of their legitimacy. This accountability is built not only on the type of actions concerned (for example, questions normatively project and expect an answer), but also on their spatiality as a relevant aspect defining their situatedness (as actions to be performed in a given place versus actions that are not bound to any particular place or spatial constraint, cf. Broth and Lundström 2013), as well as their mobile versus stationary character. In this sense, we have described actions that either orient to a prolongation of the current interactional space (such as a follow-up question to the guide) or to a new course of action that is especially bound to the place where the participants are located (such as comments involving pointing at details in the environment that are only visible and accessible from a particular viewpoint).

Given the spatial constraints exerted by delaying actions, which constitute courses of action other than the projected ones, a typical response consists in stopping the walking away. But, as we have demonstrated, participants might adopt different types of embodied responses. They may slow down without stopping, accelerate and give minimal responses, body-torque on the move, etc., manifesting different types of alignment but also of possible resistance. This makes relevant a fascinating range of diversified ways of organizing movements in space, closely related to the interactional sequential organization of actions (Mondada, 2018b).

The subtle differentiations between ways of stepping, walking and stopping to walk also raise questions concerning the rights and obligations of specific categories of participants to move in certain ways. Who initiates walking away? Who stops, and who does not? What produces the entitlement to perform an action that stops a group, or to ignore such an action? While "guides" seems to be a category bound to the right to initiate moving on but also to the obligation to stop and listen to guided parties, the distribution of rights and obligations relative to movement is not actually so clear-cut. For instance, in the energy analysis groups studied, the person guiding the group across the building is generally not the expert producing an authorized talk about specific places, and this occasions interesting complementary ways of managing the movement of the group. Likewise, delaying actions might target one participant in particular (such as the guide in visits) but also concern larger participation units (such as mobile formations of several participants), occasioning multiple discrepant responses, some of which might align and others disalign with the alternate trajectory. This further shows the extent to which delaying walking away has strong normative implications, connected to the rights and obligations of different categories of participants. 
In this sense, the paper has aimed at contributing to a better understanding of the nexus between the organization of actions, the orientation to progressivity, and the shaping of embodied mobile practices. Mobile practices such as stepping forward, walking away, slowing down, and stopping constitute a highly visible and plastic dimension of the formatting of embodied actions that can both project and delaydand accomplish or abortdthe closing of an activity and moving on to the next.

\section{Transcription conventions}

Talk has been transcribed following conventions by Gail Jefferson (2004). Embodied conduct was transcribed following conventions by Lorenza Mondada (see 2018a for a conceptual discussion, and https://franzoesistik.philhist.unibas.ch/ fileadmin/user_upload/franzoesistik/mondada_multimodal_conventions.pdf and https://www.lorenzamondada.net/ multimodal-transcription for a tutorial).

\section{Acknowledgments}

The Pier corpus was recorded by Fredrik Lundström, and was used as data in Broth and Lundström (2012). The Energy Analysis corpus was recorded by Mathias Broth. The Blandan corpus and the Archivis corpus were recorded by Lorenza Mondada with her team at ICAR Lyon. The Cooking corpus was recorded by her. The Tourly corpus was recorded by Claire Luciani as part of a project supervised by her.

We warmly thank the two anonymous reviewers for their careful, inspiring and constructive reading of previous versions of the manuscript.

\section{References}

Best, K., 2012. Making museum tours better: understanding what a guided tour really is and what a tour guide really does. Mus. Manag. Curatorsh. 27 (1), 35 e52.

Best, K., Hindmarsh, J., 2019. Embodied spatial practices and everyday organization: the work of tour guides and their audiences. Hum. Relat. 72 (2), $248 \mathrm{e} 271$.

Birkner, K., Stukenbrock, A., 2010. Multimodale Ressourcen für Stadtführungen [Multimodal resources for city tours]. In: Costa, M., Müller-Jacquier, B. (Eds.), Deutschland Als Fremde Kultur: Vermittlungsverfahren in Touristenführungen. Judicium, Munich, pp. $214 \mathrm{e} 243$.

Bolden, G.B., 2008. Reopening Russian conversations: the discourse particle -to and the negotiation of interpersonal accountability in closings. Hum. Commun. Res. 34, 99e136.

Broth, M., Lundstr6m, F., 2013. A walk on the pier. Establishing relevant places in mobile instruction. In: Haddington, P., Mondada, L., Nevile, M. (Eds.), Interaction and Mobility. Mouton de Gruyter, Berlin, pp. 91e122.

Broth, M., Mondada, L., 2013. Walking away. The embodied achievement of activity closings in mobile interactions. J. Pragmat. 47 , 41 e58.

Button, G., 1987. Moving out of closings. In: Button, G., Lee, J.R.E. (Eds.), Talk and Social Organisation. Multilingual Matters, Clevedon, pp. 101e151.

Davidson, J., 1978. An instance of negotiation in a call closing. Sociology 12 (1), 123e133.

De Stefani, E., 2006. Le chiusure conversazionali nell'interazione al banco di un supermercato [Closings in interactions at the counter of a supermarket]. In: Bürki, Y., De Stefani, E. (Eds.), Trascrivere la lingua. Dalla filologia all'analisi conversazionale. Peter Lang, Bern, pp. $369 \mathrm{e} 403$.

De Stefani, E., 2010. Reference as an interactively and multimodally accomplished practice : organizing spatial reorientation in guided tours. In: Pettorino, M., Giannini, A., Chiari, I., Dovetto, F. (Eds.), Spoken Communication. Cambridge Scholars, Newcastle upon Tyne, pp. 137e170.

De Stefani, E., Mondada, L., 2014. Reorganizing mobile formations: when "guided" participants initiate reorientations in guided tours. Space Cult. 17 (2), $157 \mathrm{e} 175$.

De Stefani, E., Mondada, L., 2017. Who's the expert? In: Van De Mieroop, D., Schnurr, S. (Eds.), Identity Struggles: Evidence from Workplaces Around the World. Benjamins, Amsterdam, pp. 95e124.

Deppermann, A., 2011. The study of formulations as a key to an interactional semantics. Hum. Stud. $34,115 e 128$.

Deppermann, A., Schmitt, R., Mondada, L., 2010. Agenda and emergence: contingent and planned activities in a meeting. J. Pragmat. 42 (6), 1700 e1718.

Garfinkel, H., Sacks, H., 1970. On formal structures of practical action. In: McKinney, J.C., Tiryakian, E.A. (Eds.), Theoretical Sociology. Appleton-CenturyClofts, New York, pp. 338e366.

Goodwin, C., 2000. Action and embodiment within situated human interaction. J. Pragmat. 32 (10), 1489 e1522.

Goodwin, C., 2017. Co-Operative Action. Cambridge University Press, Cambridge.

Haddington, P., 2019. Leave-taking as multi-activity: coordinating conversational closings with driving in cars. Lang. Commun. 65,58 e 78.

Haddington, P., Mondada, L., Nevile, M. (Eds.), 2013. Interaction and Mobility. Mouton de Gruyter, Berlin.

Heritage, J., 2007. Intersubjectivity and progressivity in person (and place) reference. In: Enfield, N.J., Levinson, S. (Eds.), Person Reference in Interaction: Linguistic, Cultural, and Social Perspectives. Cambridge University Press, Cambridge, pp. 255-280.

Heritage, J., 2011. Conversation analysis: practices and methods. In: Silverman, D. (Ed.), Qualitative Sociology, third ed. Sage, London, pp. 208e230.

Heritage, J., 2013. Turn-initial position and some of its occupants. J. Pragmat. 57, 331 e337.

Heritage, J., Maynard, D., 2006. Problems and prospects in the study of physician-patient interaction. Annu. Rev. Sociol. 32,351 e374.

Heritage, J., Sorjonen, M.-L., 1994. Constituting and maintaining activities across sequences: and-prefacing as a feature of question design. Lang. Soc. 23 (1), $1 \mathrm{e} 29$.

Jefferson, G., 2004. Glossary of transcript symbols with an introduction. In: Lerner, G.H. (Ed.), Conversation Analysis: Studies from the First Generation. Benjamins, Amsterdam, pp. $13 \mathrm{e} 31$.

Keevallik, L., 2016. Abandoning dead ends: the Estonian junction marker maitea 'I don't know'. J. Pragmat. 106, $115-128$.

Kuroshima, S., 2010. Another look at the service encounter: progressivity, intersubjectivity, and trust in a Japanese sushi restaurant. J. Pragmat. 42 (3), $856 \mathrm{e} 869$.

Linell, P., 2009. Rethinking Language, Mind, and World Dialogically. Information Age Publishing, Charlotte NC.

Mondada, L., 2014. Pointing, talk and the bodies: reference and joint attention as embodied interactional achievements. In: Seyfeddinipur, M., Gullberg, M. (Eds.), From Gesture in Conversation to Visible Utterance in Action. Benjamins, Amsterdam, pp. 95e124.

Mondada, L., 2015. Multimodal completions. In: Deppermann, A., Günthner, S. (Eds.), Temporality in Interaction. Benjamins, Amsterdam, pp. $267-307$. Professor of linguistics.

Mondada, L., 2017. Walking and talking together: questions/answers and mobile participation in guided visits. Soc. Sci. Inf. 56 (2), 1 e34. 
Mondada, L., 2018a. Multiple temporalities of language and body in interaction: challenges for transcribing multimodality. Res. Lang. Soc. Interact. 51 (1), $85 \mathrm{e} 106$.

Mondada, L., 2018b. Questions on the move. The ecology and temporality of question/answers in mobility settings. In: Deppermann, A., Streeck, J. (Eds.), Modalities and Temporalities. Benjamins, Amsterdam, pp. $161 \mathrm{e} 202$.

Muntigl, P., 2013. Resistance in couples counselling: sequences of talk that disrupt progressivity and promote disaffiliation. J. Pragmat. 49 (1), $18-37$. Nevile, M., 2006. Making sequentiality salient: and-prefacing in the talk of airline pilots. Discourse Stud. 8 (2), $279-302$.

Ryave, A.L., Schenkein, J.N., 1974. Notes on the art of walking. In: Turner, R. (Ed.), Ethnomethodology. Penguin, Harmondsworth, pp. 265 e274.

Sacks, H., 1972. An initial investigation of the usability of conversational materials for doing sociology. In: Sudnow, D. (Ed.), Studies in Social Interaction. Free Press, New York, pp. 31 e74.

Sacks, H., Schegloff, E.A., Jefferson, G., 1974. A simplest systematics for the organization of turn-taking for conversation. Language 50 (4), $696 e 735$.

Sacks, H., 1992. Lectures on Conversation [1964-72], 2 Vols. Basil Blackwell, Ox ford.

Schegloff, E.A., 1979. The relevance of repair for syntax-for-conversation. In: Givon, T. (Ed.), Syntax and Semantics, vol. 12. Academic Press, New York, pp. 261e288. Discourse and Syntax.

Schegloff, E.A., 1998. Body torque. Soc. Res. 65 (3), 535 e586.

Schegloff, E.A., 2007. In: Sequence Organization in Interaction: A Primer in Conversation Analysis, vol. 1. Cambridge University Press, Cambridge.

Schegloff, E.A., Sacks, H., 1973. Opening up closings. Semiotica 8 (4), 289 e327.

Stivers, T., Robinson, J.D., 2006. A preference for progressivity in interaction. Lang. Soc. 35 (3), $367 \mathrm{e} 392$.

Mathias Broth is professor of language and culture at Linköping University. His research is based on detailed analyses of video recordings of a range of situations - where people speak French, Swedish or English - and deals with everyday and professional ways of accomplishing social actions. How people close down conversational sequences, theatre goers laugh together, television production crews live-edit studio interviews, and learn to drive in driving schools, how news in print and for the web is created at a Swedish media house are some of the topics he has studied. He has co-edited several journal special issues and books (for, e.g., J. of Pragmatics, Space \& Culture, Language and Communication, Routledge) on topics related to language and social interaction.

Lorenza Mondada is professor of linguistics at the University of Basel. Her research deals with social interaction in ordinary, professional and institutional settings, within an ethnomethodological and conversation analytic perspective. Her focus is on video analysis and multimodality, researching how the situated and endogenous organization of social interaction draws on a diversity of multimodal resources such as, beside language, gesture, gaze, body posture, movements, objets manipulations as well as multisensorial pracices such as touching, tasting and seeing. She has extensively published in J. of Pragmatics, Discourse Studies, Language in Society, ROLSI, J. of Sociolinguistics, and co-edited several collective books. 